\title{
Development and validation of a GC-MS/MS method for the determination of 11 amphetamines and 34 synthetic cathinones in whole blood
}

\author{
Mateusz Kacper Woźniak ${ }^{1}$ (D) Laura Banaszkiewicz $^{1} \cdot$ Marek Wiergowski $^{2} \cdot$ Ewa Tomczak $^{2} \cdot$ Marzena Kata $^{2}$. \\ Beata Szpiech ${ }^{2}$. Jacek Namieśnik ${ }^{1}$ - Marek Biziuk
}

Received: 24 March 2019 / Accepted: 25 May 2019 / Published online: 26 June 2019

(c) The Author(s) 2019

\begin{abstract}
Purpose Psychoactive compounds that contain a phenylethylamine structure (such as amphetamine-type stimulants and synthetic cathinones) are one of the major classes of stimulants on the recreational drug market. Approximately 670 new psychoactive substances (NPS) are monitored only in Europe; however, new psychoactive compounds are being developed for illicit trade each year. In this context, the development of new analytical procedures for the determination of such compounds in biological specimens for forensic toxicology is of great importance.

Methods Gas chromatography-tandem mass spectrometry (GC-MS/MS) technique was applied for analysis of amphetamines and synthetic cathinones. The volumes of $200 \mu \mathrm{L}$ of each whole blood sample and $1 \mathrm{~mL}$ of liquid-liquid extraction solvent were used for extraction, followed by pentafluoropropionyl derivatization.

Results A high-throughput, robust, rapid, and sensitive procedure involving a simple liquid-liquid extraction for the simultaneous determination of 45 amphetamine-type stimulants and synthetic cathinones in whole blood was developed. The assay was validated based on its recovery $(83.2-106 \%)$, interday accuracy $(89.0-108 \%)$, and interday precision $(\leq 8.1 \%)$. In view of the low limits of detection (ranged between 0.02 and $0.72 \mathrm{ng} / \mathrm{mL}$ ) and limits of quantification $(1 \mathrm{and} 2.5 \mathrm{ng} / \mathrm{mL}$ ), the developed method can serve as a less expensive and more ecologically friendly alternative to the liquid chromatography-tandem mass spectrometric methods.

Conclusions To the best of our knowledge, this is the first work presenting a GC-MS/MS method for the determination of NPS in blood samples. The presented procedure was applied to authentic samples from forensic cases, demonstrating its utility in the quantification of a wide number of psychoactive substances in routine toxicological analyses. The developed procedure can also be easily expanded to additional compounds.
\end{abstract}

Keywords Amphetamine-type stimulants (ATSs) · Synthetic cathinones $\cdot$ Whole blood $\cdot$ GC-MS/MS

Prof. Jacek Namieśnik passed away on 14 April 2019. He will always remain in our memory.

Electronic supplementary material The online version of this article (https://doi.org/10.1007/s11419-019-00485-y) contains supplementary material, which is available to authorized users.

Mateusz Kacper Woźniak mateusz.wozniak@pg.edu.pl

1 Department of Analytical Chemistry, Faculty of Chemistry, Gdańsk University of Technology, 11/12 Narutowicza Str., 80-233 Gdańsk, Poland

2 Department of Forensic Medicine, Faculty of Medicine, Medical University of Gdańsk, 3A Marii Skłodowskiej-Curie Str., 80-210 Gdańsk, Poland

\section{Introduction}

Despite many campaigns against drug use and increasing public understanding of their potential harmful health effects, the abuse of recreational drugs still poses serious social and economic problems worldwide [1]. Currently, the use of both classic drugs and new psychoactive substances (NPS) is very popular, especially among young people. These types of drugs all tend to stimulate the central nervous system and offer hallucinogenic and psychedelic effects, which makes their use attractive. According to the newest Drug Report published in 2018 by the European Monitoring Centre for Drugs and Drug Addiction (EMCDDA), at 
the end of 2017 , more than 670 NPS were monitored only in Europe [2].

Although the number of new drugs making their debut is down from its peak in 2015, the current drug market is still very fluid and dynamic. Many new compounds belonging to various classes are introduced for illicit trade each year worldwide, with 51 new substances detected for the first time only in Europe in 2017 [2]. Psychoactive compounds that contain a phenylethylamine (PEA) core are one of the major classes of stimulants on the recreational drug market. These include both classic drugs, such as amphetamine-type stimulants (ATSs), and NPS, especially $\beta$-keto-amphetamines analogues known as synthetic cathinones, which are growing in popularity. PEA derivatives constitute approximately $37 \%$ of the NPS present on the black market [3].

Among ATSs, amphetamine (AM), methamphetamine (MA), phentermine (PM), 3,4-methylenedioxyamphetamine (MDA), 3,4-methylenedioxymethamphetamine (MDMA), and 3,4-methylenedioxy- $N$-ethylamphetamine (MDEA) are the most commonly used drugs after cannabis products [1]. In addition, seizures of MA and MDMA have recently increased by 21 and $122 \%$, respectively [3].

NPS are typically synthesized as analogues of existing drugs to bypass laws and regulations and/or to provide enhanced pharmacological activities relative to the existing compounds, from which they are derived. These substances are commonly sold via the Internet under slang terms such as 'legal highs' for drugs in the form of powder or tablets and 'herbal highs' for products in the plant form. They are sold for use only as collectibles and officially absolutely not intended for human consumption; therefore, there is no information on the dosage for safe use. This constitutes an additional danger to human health $[4,5]$.

A diverse range of $\beta$-keto-amphetamine analogues has been synthesized and sold as a 'legal' alternative to ATSs. This is due to their similar psychostimulating effects following their use and because they are perceived to be pure and to have fewer health risks as compared to classic drugs of abuse. However, in recent years, the use of these new stimulants has resulted in serious acute and even fatal toxicities, increasing the importance of their determination in biological specimens in forensic toxicology. In addition, the dangers are seriously enhanced by polydrug use, which is a common pattern of NPS use. For examples, such situations can be observed when ATSs and synthetic cathinones are taken together because of their similar mechanism of action [5-7].

Several analytical challenges are associated with the identification and quantification of NPS in biological samples, such as the large number of potential structures (including isomers that are difficult to separate using chromatographic techniques), the constant introduction of novel compounds and the low concentrations typically found in real samples due to the fact that only small doses are necessary for the psychoactive effects. Furthermore, NPS are rarely detected by most immunoassay screening tests used for routine drug screenings, and there is a high possibility of false positive results because of cross-reactions with other drugs. In addition, these NPS can be impossible to detect because of the continuous introduction of structural derivatives. To overcome these challenges, the use of novel, selective and sensitive hyphenated techniques, especially based on mass spectrometry (MS), is required for NPS analysis. Additionally, the use of such techniques allows the determination of many substances in one analytical method, which reduces the time and cost of the screening. Among them, gas chromatography and liquid chromatography coupled with mass spectrometry (GC-MS and LC-MS/MS) are the most preferred techniques in forensic and clinical toxicology laboratories [3, 8, 9]. In recent years, several analytical methods utilizing both GC and LC have been developed for the analysis of multiple PEA derivatives in biological specimens $[3,4,6,8,10]$. Although LC-MS/MS-based assays have been proven to be selective, accurate and precise for the separation, detection and quantification of designer cathinones and related drugs in biological samples, they require a large volume of organic solvent for chromatographic separation $[8,10]$. According to the principles of "green analytical chemistry," GC methods hyphenated with MS are most attractive because the mobile phase in GC-based methods may not cause serious environmental pollution [11]. Thus, substantial attention is being paid to the development of procedures based on GC-MS/MS for routine toxicology analyses due to the sufficient selectivity and sensitivity of this technique for the determination of trace analytes in complex biological matrices [1,12-16]. It has also been suggested that GC-MS/MS-based methods can be a less expensive and more environmentally friendly as compared to LC-MS/MS-based analyses [1]. Until now, GC-MS/MS has only been successfully utilized for the identification of NPS in seized materials [17] and not for the analysis of biological specimens.

In our previous study [1], we applied GC-MS/MS to analyses of six ATSs, including AM, MA, PM, MDA, MDMA, and MDEA in human whole blood and urine for the first time. Thus, the aim of this study was to develop a highthroughput, robust, rapid, selective and sensitive GC-MS/ MS-based procedure with a simple liquid-liquid extraction (LLE) as the sample preparation step for the simultaneous determination of the 45 most commonly reported ATSs and synthetic cathinones in whole blood samples in a single run. The six ATSs described in the previous report [1] were also included in the present study, because the previous derivatization was somewhat different from the present one, and their inclusion in this study seemed useful for comparing their retention times with those of other drugs. Minimizing the sample volume required for the extraction while maintaining sufficient sensitivity for the quantification of 
low concentrations of NPS as compared to other published methods was also a priority. The applicability of the developed method was demonstrated by analysing samples from medicolegal cases in which drug use was suspected.

\section{Materials and methods}

\section{Chemicals and reagents}

The certified standards of drugs (purity $\geq 98 \%$ ) used in this study were purchased from commercial suppliers, including Cayman Chemical (Ann Arbor, MI, USA), Cerilliant (Round Rock, TX, USA), Chiron (Trondheim, Norway) and LGC Standards (London, UK). The standards were delivered as solutions in methanol $(\mathrm{MeOH})$ at concentrations of 0.25 or $1 \mathrm{mg} / \mathrm{mL}$ or in powder forms in batches of 1,5 , or $10 \mathrm{mg}$. The powders were individually dissolved in $\mathrm{MeOH}$ to obtain concentrations at $1 \mathrm{mg} / \mathrm{mL}$. All of the prepared solutions were used as the stock standard solutions. Solutions of racmethamphetamine- $\mathrm{D}_{5}\left(\right.$ rac $\left.-\mathrm{mAMP}-\mathrm{D}_{5}\right)$ and cathinone- $\mathrm{D}_{5}$ $\left(\right.$ Cat- $\left.\mathrm{D}_{5}\right)$ in $\mathrm{MeOH}$ at concentrations of 0.1 and $1 \mathrm{mg} / \mathrm{mL}$, respectively, were used as internal standards (ISs). Details on the sources of all standards and their forms with abbreviations, common names, IUPAC names, and substance classes are listed in Table $\mathrm{S} 1$ in the supplementary material.

All solvents used were of HPLC grade and were supplied by Sigma-Aldrich (St. Louis, MO, USA), and pentafluoropropionic anhydride (PFPA) for GC derivatization (99\% purity) was obtained from the same source. Analyticalgrade sodium hydroxide $(\mathrm{NaOH})$ powder and hydrochloric acid $(\mathrm{HCl})$ at a concentration of $35-38 \%$ were obtained from POCH S.A. (Gliwice, Poland). Water was purified by a Millipore Milli-Q Gradient A10 water system (Merck, Warszawa, Poland).

The solution of $0.1 \mathrm{M} \mathrm{NaOH}$ was obtained by dissolving the appropriate mass of $\mathrm{NaOH}$ powder in ultra-pure water. Methanolic $\mathrm{HCl}$ solution was prepared by mixing both chemicals in a volume ratio of 9:1.

\section{Biological specimens}

Drug-free (blank) blood samples, collected from volunteers who were not consumers of any drug, were obtained from a regional blood donation bank (Gdańsk, Poland), and were used for the development and validation of the method. Blank blood samples were stored at $-20{ }^{\circ} \mathrm{C}$ prior to analysis.

Authentic (real) blood samples were sent to the Department of Forensic Medicine (Medial University of Gdańsk, Poland) or collected during an ongoing autopsy in 2017 and 2018 for routine toxicological analyses of psychoactive substances and prescription drugs. Samples positive for NPS (based on preliminary testing using in-house-developed
LC-MS/MS- and GC-MS-based screening methods performed during routine toxicology analyses) were subjected to analyses based on existing collaborations between the Medical University of Gdańsk and Gdańsk University of Technology. The samples were kept at $-20{ }^{\circ} \mathrm{C}$ until analysis, as suggested by stability studies [18-20].

\section{Stock solutions, calibrators, and quality control samples}

Mixed stock solutions of the analytes were prepared in $\mathrm{MeOH}$ by diluting the standard solutions to concentrations of $0.1,1$, and $10 \mu \mathrm{g} / \mathrm{mL}$ (stock solutions of chromatographically unresolved compounds were prepared separately, and validation was performed in other experiment as described in "GC-MS/MS optimization" of "Results and discussion"). The IS mixture was prepared in $\mathrm{MeOH}$ at a concentration of $1 \mu \mathrm{g} / \mathrm{mL}$ and was used as an IS stock solution. These solutions were used for calibration and validation. All solutions were stored at $-20{ }^{\circ} \mathrm{C}$ until use.

The calibration solutions were prepared in triplicate ( $n=3$ ) by spiking $200 \mu \mathrm{L}$ of drug-free blood with the appropriate stock solutions of the analytes to obtain concentrations of $1,2.5,5,10,25,50,100$, and $250 \mathrm{ng} / \mathrm{mL}$. The concentration of the ISs in each sample was maintained at $25 \mathrm{ng} / \mathrm{mL}$ by adding $5 \mu \mathrm{L}$ of the IS stock solution. Then, the extraction and derivatization procedure was performed.

Quality control (QC) samples for most analytes were prepared in a manner similar to that used to prepare the calibrators at three concentration levels within the linear range of the assay $(n=6)$; low: $2.5 \mathrm{ng} / \mathrm{mL}$ (LQC), medium: $25 \mathrm{ng} / \mathrm{mL}$ (MQC), and high: $200 \mathrm{ng} / \mathrm{mL}$ (HQC). For MDPBP, MDPV, and naphyrone, in view of their weaker signal in this detector, the LQC samples were prepared at a concentration of $5 \mathrm{ng} / \mathrm{mL}$. QC samples were used to investigate the repeatability of the method and the stability of the analytes.

\section{Sample preparation}

After optimization, the following workflow was employed: in a 1.5-mL Eppendorf vial, $0.2 \mathrm{~mL}$ of blood or QC sample was mixed with $5 \mu \mathrm{L}$ of the IS stock solution and $200 \mu \mathrm{L}$ of $0.1 \mathrm{M} \mathrm{NaOH}$ solution (to obtain a pH of approximately 12). Then, $1 \mathrm{~mL}$ of ethyl acetate was added, and the sample was vortexed for $1 \mathrm{~min}$ and then centrifuged at 13,000 rpm $(11,400 \times g)$ for $2 \mathrm{~min}$. The organic layer was transferred to a glass vial. Next, $100 \mu \mathrm{L}$ of $\mathrm{HCl}$ solution in $\mathrm{MeOH}$ was added to the extract, and the solution was concentrated under a gentle stream of nitrogen at $40{ }^{\circ} \mathrm{C}$. The dry residue was reconstituted in $50 \mu \mathrm{L}$ of ethyl acetate. The sample was derivatized by adding $50 \mu \mathrm{L}$ of PFPA and incubating the mixture at $55^{\circ} \mathrm{C}$ for $20 \mathrm{~min}$. Then, the solution was evaporated to dryness. Importantly, the evaporation was stopped 
immediately after the solvent had evaporated because the derivatized analytes are volatile. The residue was dissolved in $50 \mu \mathrm{L}$ of dichloromethane (DCM) and transferred to a $150-\mu \mathrm{L}$ insert for an autosampler vial. Two microliters of the sample was injected into the GC-MS/MS system.

Real samples with concentrations above the range of the calibration curve were diluted with drug-free blood (the same blood that was used for the validation studies) to perform the quantification within the ranges of the calibration curves.

\section{GC-MS/MS conditions}

All analyses were performed using a GC-2010 PLUS system equipped with a split/splitless injection port and an AOC6000 autosampler (Shimadzu, Kyoto, Japan). The analytes were separated on a Zebron ZB-5MSi capillary column (30 $\mathrm{m} \times 0.25-\mathrm{mm}$ id, and $0.25-\mu \mathrm{m}$ film thickness; Phenomenex, Torrance, CA, USA). Helium (grade 5.0) was used as the carrier gas (initial flow rate of $1 \mathrm{~mL} / \mathrm{min}$ ). Then, a constant gas linear velocity of $36.3 \mathrm{~cm} / \mathrm{s}$ was maintained. Splitless injection mode was used for 0.5 min followed by split mode (20:1) to obtain high sensitivity and to further remove residues of impurities from the injection port and column. The oven temperature gradient program was as follows: hold an initial temperature of $50^{\circ} \mathrm{C}$ for $1 \mathrm{~min}$, ramp to $160{ }^{\circ} \mathrm{C}$ at $15^{\circ} \mathrm{C} / \mathrm{min}$, then ramp to $250{ }^{\circ} \mathrm{C}$ at $5^{\circ} \mathrm{C} / \mathrm{min}$, ramp to $300{ }^{\circ} \mathrm{C}$ at $20^{\circ} \mathrm{C} / \mathrm{min}$, and finally hold for $1 \mathrm{~min}$. A solvent delay time of $8 \mathrm{~min}$ was used. The column was reconditioned at $300{ }^{\circ} \mathrm{C}$ for $2 \mathrm{~min}$ to eliminate all impurities co-extracted from the matrix and minimize carry-over effects. The temperatures of the injection port and MS transfer line were 260 and $285^{\circ} \mathrm{C}$, respectively.

The GC instrument was directly interfaced to a GCMSTQ8050 triple quadrupole mass spectrometer (Shimadzu). The MS analyses were conducted in positive electron ionization (EI) mode with a filament current at $60 \mu \mathrm{A}$. An ionization energy at $70 \mathrm{eV}$ was applied. The ion source temperature was set at $250{ }^{\circ} \mathrm{C}$. For ion fragmentation, argon (grade 5.0) was used as the collision-induced dissociation (CID) gas. Quantifications were performed using multiple reaction monitoring (MRM) transitions. The specific transitions and the optimum collision energies (CEs) for all compounds are listed in Table 1. The MS detector run was set at $17 \mathrm{~min}$. The data were handled and the system was operated using GCMS Solution and Insight GCMS software (version 4.45; Shimadzu).

\section{Identification criteria}

The criteria used for the identification of analytes were retention time (RT), the presence of two characteristic MRM transitions, and the relative intensities for the transitions. For the identification of the analytes in MS/MS-based methods, RT and the relative MRM transition intensities should not vary by more than $\pm 1 \%$ and $\pm 20 \%$, respectively, relative to a spiked control sample [21].

\section{Method validation}

The developed procedure was validated according to international guidelines in the field of our study [22, 23]. Under the optimized conditions, several parameters relevant for a quantitative method, namely, the selectivity, matrix effects, linearity, limit of detection (LOD), limit of quantification (LOQ), carry-over effects, recovery, repeatability, and stability, were evaluated. The validation parameters were calculated by introducing the respective formulas into a Microsoft Excel worksheet.

\section{Selectivity}

The selectivity was verified by analysing blood samples collected from various individuals not suspected of drug use. The samples were analysed for the presence of peaks that could interfere with the substances of interest. Due to the potential applications of this method for both fatal and nonfatal cases, the selectivity tests were performed on samples collected antemortem and those collected postmortem (10 samples for each case), because differences in the matrix composition can be observed.

\section{Matrix effects}

To verify the suppression or enhancement of the signals due to the influence of the sample matrix, seven or eight calibration solutions (as described in "Stock solutions, calibrators and quality control samples") were prepared in triplicate $(n=3)$ in $\mathrm{MeOH}$ as well as in extracts obtained from blank blood samples. Then, both calibration curves were constructed by plotting the peak area ratios (analytes vs. IS) against the corresponding concentrations. The matrix effects (MEs) were calculated by comparing the slopes of the two calibration curves $\left[a_{\mathrm{m}}\right.$ is the slope of the calibration curve prepared in blank blood extract (matrix), and $a_{\mathrm{s}}$ is the slope of the calibration curve prepared in solvent] using the following formula:

$\operatorname{ME}[\%]=\left(\frac{a_{\mathrm{m}}}{a_{\mathrm{s}}}-1\right) \times 100 \%$

\section{Calibration, linearity, LOD, and LOQ}

Seven- or eight-point calibration curves (depending on the MS response, see "Method validation" of "Results and discussion") were constructed (by plotting the analyte peak 
Table 1 Retention times and parameters for multiple reaction monitoring mode for the studied analytes and ISs

\begin{tabular}{|c|c|c|c|c|c|c|c|c|c|}
\hline \multirow[t]{2}{*}{ No. } & \multirow[t]{2}{*}{ Compound } & \multirow[t]{2}{*}{ RT (min) } & \multicolumn{2}{|l|}{ Quantifier } & \multicolumn{2}{|l|}{ Qualifier } & \multirow[t]{2}{*}{ RA } & \multirow[t]{2}{*}{ Derivatization } & \multirow[t]{2}{*}{ IS } \\
\hline & & & Transition $(m / z)$ & $\mathrm{CE}(\mathrm{V})$ & Transition $(m / z)$ & $\mathrm{CE}(\mathrm{V})$ & & & \\
\hline 1 & Amphetamine & 8.67 & $118.2 \rightarrow 91.1$ & 27 & $190.1 \rightarrow 69.1$ & 27 & $100 / 60$ & Yes & mAMP-D $_{5}$ \\
\hline 2 & Phentermine & 8.80 & $204.2 \rightarrow 59.1$ & 12 & $204.2 \rightarrow 69.1$ & 33 & $100 / 20$ & Yes & $\mathrm{mAMP} \mathrm{D}_{5}$ \\
\hline 3 & Ephedrine & 9.75 & $204.2 \rightarrow 160.1$ & 12 & $204.2 \rightarrow 119.0$ & 24 & $100 / 78$ & Yes & $\mathrm{mAMP} \mathrm{D}_{5}$ \\
\hline 4 & $\mathrm{mAMP}^{-\mathrm{D}_{5}}$ & 9.79 & $208.2 \rightarrow 163.1$ & 12 & $208.2 \rightarrow 119.1$ & 24 & $100 / 78$ & Yes & IS \\
\hline 5 & Methamphetamine & 9.82 & $204.2 \rightarrow 160.1$ & 12 & $204.2 \rightarrow 119.0$ & 27 & $100 / 58$ & Yes & mAMP-D $_{5}$ \\
\hline 6 & Cat-D 5 & 9.94 & $110.2 \rightarrow 82.2$ & 12 & $110.2 \rightarrow 54.2$ & 27 & $100 / 43$ & Yes & IS \\
\hline 7 & Cathinone & 9.97 & $105.1 \rightarrow 77.1$ & 15 & $105.1 \rightarrow 51.1$ & 27 & $100 / 39$ & Yes & Cat-D ${ }_{5}$ \\
\hline 8 & Pseudoephedrine & 10.39 & $204.2 \rightarrow 160.1$ & 12 & $204.2 \rightarrow 119.0$ & 27 & $100 / 47$ & Yes & mAMP-D $_{5}$ \\
\hline 9 & 4-MMA & 10.86 & $132.2 \rightarrow 117.2$ & 12 & $204.2 \rightarrow 160.1$ & 9 & $100 / 95$ & Yes & mAMP-D $_{5}$ \\
\hline 10 & Ethcathinone & 11.23 & $105.1 \rightarrow 77.1$ & 12 & $105.1 \rightarrow 51.1$ & 27 & $100 / 45$ & Yes & Cat- $\mathrm{D}_{5}$ \\
\hline 11 & PMA & 11.27 & $121.2 \rightarrow 78.1$ & 27 & $121.2 \rightarrow 91.1$ & 12 & $100 / 45$ & Yes & mAMP-D $_{5}$ \\
\hline 12 & 2-MMC & 11.31 & $119.1 \rightarrow 91.1$ & 12 & $119.1 \rightarrow 65.1$ & 27 & $100 / 40$ & Yes & Cat- $\mathrm{D}_{5}$ \\
\hline 13 & 3-MMC & 11.35 & $119.1 \rightarrow 91.1$ & 12 & $119.1 \rightarrow 65.1$ & 27 & $100 / 45$ & Yes & Cat-D ${ }_{5}$ \\
\hline 14 & 4-MMC & 11.64 & $119.1 \rightarrow 91.1$ & 12 & $119.1 \rightarrow 65.1$ & 27 & $100 / 45$ & Yes & Cat- $\mathrm{D}_{5}$ \\
\hline 15 & Pentedrone & 11.96 & $190.2 \rightarrow 119.0$ & 15 & $232.2 \rightarrow 190.1$ & 12 & $100 / 98$ & Yes & Cat- $\mathrm{D}_{5}$ \\
\hline 16 & 4-CMC & 12.41 & $204.2 \rightarrow 160.1$ & 12 & $204.2 \rightarrow 119.1$ & 24 & $100 / 65$ & Yes & Cat-D ${ }_{5}$ \\
\hline 17 & 3-CMC & 12.47 & $204.2 \rightarrow 160.1$ & 12 & $204.2 \rightarrow 119.1$ & 24 & $100 / 65$ & Yes & Cat- $D_{5}$ \\
\hline 18 & MDA & 12.61 & $135.1 \rightarrow 77.1$ & 18 & $135.1 \rightarrow 51.1$ & 27 & $100 / 70$ & Yes & mAMP-D $_{5}$ \\
\hline 19 & 4-MEC & 12.64 & $119.1 \rightarrow 91.1$ & 12 & $119.1 \rightarrow 65.1$ & 27 & $100 / 44$ & Yes & Cat- $\mathrm{D}_{5}$ \\
\hline 20 & PMMA & 12.87 & $121.1 \rightarrow 78.1$ & 21 & $121.1 \rightarrow 91.1$ & 12 & $100 / 55$ & Yes & mAMP-D 5 \\
\hline 21 & 4-EMC & 12.89 & $133.2 \rightarrow 77.1$ & 27 & $133.2 \rightarrow 105.1$ & 9 & $100 / 93$ & Yes & Cat- $D_{5}$ \\
\hline 22 & 3,4-DMMC & 13.20 & $133.2 \rightarrow 105.1$ & 12 & $133.2 \rightarrow 77.1$ & 27 & $100 / 65$ & Yes & Cat- $\mathrm{D}_{5}$ \\
\hline 23 & 4-MPD & 13.45 & $119.1 \rightarrow 91.1$ & 12 & $119.1 \rightarrow 65.1$ & 24 & $100 / 47$ & Yes & Cat-D 5 \\
\hline 24 & $N$-Propylpentedrone & 13.45 & $260.2 \rightarrow 55.1$ & 21 & $260.2 \rightarrow 218.2$ & 9 & $100 / 80$ & Yes & Cat- $\mathrm{D}_{5}$ \\
\hline 25 & 3-CEC & 13.49 & $218.2 \rightarrow 190.1$ & 9 & $218.2 \rightarrow 119.0$ & 27 & $100 / 48$ & Yes & Cat- $\mathrm{D}_{5}$ \\
\hline 26 & 4-CEC & 13.49 & $218.2 \rightarrow 190.1$ & 9 & $218.2 \rightarrow 119.0$ & 27 & $100 / 50$ & Yes & Cat- $D_{5}$ \\
\hline 27 & Hex-en & 13.99 & $260.2 \rightarrow 69.1$ & 15 & $204.2 \rightarrow 176.1$ & 9 & $100 / 56$ & Yes & Cat- $\mathrm{D}_{5}$ \\
\hline 28 & Methedrone & 14.00 & $135.1 \rightarrow 77.1$ & 15 & $135.1 \rightarrow 92.1$ & 24 & $100 / 46$ & Yes & Cat- $\mathrm{D}_{5}$ \\
\hline 29 & 4-CPD & 14.22 & $232.2 \rightarrow 119.0$ & 15 & $232.2 \rightarrow 55.1$ & 15 & $100 / 24$ & Yes & Cat-D 5 \\
\hline 30 & MDMA & 14.40 & $204.2 \rightarrow 160.1$ & 9 & $162.2 \rightarrow 104.2$ & 15 & $100 / 60$ & Yes & mAMP-D $_{5}$ \\
\hline 31 & MDEA & 15.01 & $218.2 \rightarrow 190.1$ & 9 & $162.2 \rightarrow 104.1$ & 18 & $100 / 67$ & Yes & $\mathrm{mAMP} \mathrm{D}_{5}$ \\
\hline 32 & $\alpha-P V P$ & 15.04 & $126.2 \rightarrow 97.1$ & 12 & $126.2 \rightarrow 69.1$ & 24 & $100 / 91$ & No & Cat- $\mathrm{D}_{5}$ \\
\hline 33 & Methylone & 15.45 & $149.1 \rightarrow 65.1$ & 21 & $149.1 \rightarrow 121.1$ & 12 & $100 / 91$ & Yes & Cat- $\mathrm{D}_{5}$ \\
\hline 34 & $\alpha-\mathrm{PiHP}$ & 15.54 & $140.3 \rightarrow 98.2$ & 12 & $140.3 \rightarrow 84.1$ & 9 & $100 / 43$ & No & Cat- $\mathrm{D}_{5}$ \\
\hline 35 & 4-F-PHP & 16.05 & $140.3 \rightarrow 69.1$ & 21 & $140.3 \rightarrow 84.1$ & 12 & $100 / 84$ & No & Cat- $\mathrm{D}_{5}$ \\
\hline 36 & Butylone & 16.32 & $149.1 \rightarrow 65.2$ & 27 & $149.1 \rightarrow 121.1$ & 12 & $100 / 99$ & Yes & Cat-D 5 \\
\hline 37 & $\alpha-\mathrm{PHP}$ & 16.56 & $140.3 \rightarrow 84.1$ & 12 & $140.3 \rightarrow 69.1$ & 18 & $100 / 92$ & No & Cat-D 5 \\
\hline 38 & Eutylone & 17.27 & $149.1 \rightarrow 65.1$ & 21 & $149.1 \rightarrow 121.1$ & 12 & $100 / 75$ & Yes & Cat-D 5 \\
\hline 39 & Pentylone & 17.53 & $149.1 \rightarrow 65.1$ & 21 & $149.1 \rightarrow 121.1$ & 12 & $100 / 87$ & Yes & Cat- $\mathrm{D}_{5}$ \\
\hline 40 & 4-Cl- $\alpha-\mathrm{PVP}$ & 17.91 & $126.2 \rightarrow 69.1$ & 21 & $126.2 \rightarrow 97.1$ & 15 & $100 / 98$ & No & Cat-D 5 \\
\hline 41 & Ephylone & 18.41 & $149.1 \rightarrow 65.1$ & 24 & $149.1 \rightarrow 121.1$ & 12 & $100 / 93$ & Yes & Cat-D 5 \\
\hline 42 & PV4 (MPHP) & 18.55 & $140.3 \rightarrow 69.1$ & 21 & $140.3 \rightarrow 84.1$ & 12 & $100 / 86$ & No & Cat- $\mathrm{D}_{5}$ \\
\hline 43 & PV9 & 19.92 & $168.3 \rightarrow 84.2$ & 12 & $168.3 \rightarrow 69.2$ & 27 & $100 / 66$ & No & Cat- $D_{5}$ \\
\hline 44 & MDPBP & 20.24 & $112.2 \rightarrow 70.2$ & 12 & $112.2 \rightarrow 55.2$ & 18 & $100 / 85$ & No & Cat-D 5 \\
\hline 45 & MDPV & 21.51 & $126.2 \rightarrow 69.2$ & 18 & $126.2 \rightarrow 97.2$ & 12 & $100 / 95$ & No & Cat- $\mathrm{D}_{5}$ \\
\hline 46 & 3,4-MDPHP & 23.02 & $140.3 \rightarrow 69.2$ & 21 & $140.3 \rightarrow 84.2$ & 12 & $100 / 82$ & No & Cat-D 5 \\
\hline 47 & Naphyrone & 24.59 & $126.2 \rightarrow 69.2$ & 27 & $126.2 \rightarrow 97.2$ & 15 & $100 / 75$ & No & Cat- $\mathrm{D}_{5}$ \\
\hline
\end{tabular}

$R T$ retention time, $C E$ collision energy, $R A$ relative abundance (quantifier/qualifier ions), $I S$ internal standard, $m A M P-D_{5}$ methamphetamine$\mathrm{D}_{5}$, Cat-D5 cathinone- $\mathrm{D}_{5}, 4-M M A$ 4-methylmethamphetamine, $P M A p$-methoxyamphetamine, $M M C$ methylmethcathinone, $C M C$ chloromethcathinone, $M D A$ 3,4-methylenedioxyamphetamine, 4-MEC 4-methylethcathinone, $P M M A$ p-methoxymethamphetamine, 4-EMC 4-ethylmethcathinone, 3,4-DMMC 3,4-dimethylmethcathinone, 4-MPD 4-methylpentedrone, $C E C$ chloroethcathinone, hex-en $N$-ethylhexedrone, 4-CPD 4-chloropentedrone, MDMA 3,4-methylenedioxymethamphetamine, $M D E A$ 3,4-methylenedioxy- $N$-ethylamphetamine, $\alpha$-PVP $\quad \alpha$-pyrrolidinopentiophenone, $\alpha$-PiHP $\quad \alpha$-pyrrolidinoisohexanophenone, $\quad 4-F-P H P \quad$ 4-fluoro- $\alpha$-pyrrolidinohexanophenone, $\alpha$ - $P H P$ 
Table 1 (continued)

$\alpha$-pyrrolidinohexanophenone, $P V 4$ 4-methyl- $\alpha$-pyrrolidinohexanophenone, $P V 9 \alpha$-pyrrolidinooctanophenone, MDPBP 3,4-methylenedioxy- $\alpha$ pyrrolidinobutiophenone, $M D P V$ 3,4-methylenedioxypyrovalerone, 3,4-MDPHP 3,4-methylenedioxy- $\alpha$-pyrrolidinohexanophenone

areas relative to the corresponding IS peak area versus the analyte concentration). The linearity of the calibration curves was verified in the range of $1-250 \mathrm{ng} / \mathrm{mL}$ or $2.5-250 \mathrm{ng} / \mathrm{mL}$ and was assessed as the correlation coefficient $(r)$. The LOD for each compound was taken as the concentration giving a signal-to-background noise ratio $(\mathrm{S} / \mathrm{N}$ ratio) of at least 3 for the lower intensity MRM transition. The LOQ was assumed as the lowest point of the calibration curve subject to the linearity.

\section{Carry-over effect, recovery, and repeatability}

The carry-over effects were established by analysing blank blood sample extracts after the highest calibrator. The tests were performed six times. The recovery of each analyte was verified at three concentration levels (the levels used for the QC samples) and calculated as the ratio of the analyte-to-IS peak area ratio of the spiked and extracted drug-free blank blood samples to the corresponding analyte-to-IS peak area ratio of the matrix extracts spiked with the standard $(n=6)$. Importantly, the IS stock solution was added post-extraction to avoid loss of the IS during the extraction step. The repeatability of the developed method was evaluated as the intraand inter-assay accuracy and precision. For this purpose, QC samples were analysed six times $(n=6)$. The analyses were repeated over 3 days to estimate the interday assay repeatability from the between-day averages. The accuracy (A\%) was calculated as the ratio of the mean measured concentration to the nominal concentration. The precision was evaluated as the coefficients of variation of these measurements.

\section{Stability of the analytes}

The instability of analytes mainly complicates storage. Therefore, this knowledge is crucial to preventing analyte degradation in samples of biological origin. Analyte degradation can lead to underestimation of the real concentration or even to no detection, which would lead to unreliable results. Recently, increased interest in the stability of NPS in biological materials has been observed because many of these compounds have been assumed to be unstable during storage. In 2019, Adamowicz and Malczyk [24] published a comprehensive study on the stability of NPS in blood and urine samples during storage under various conditions. The results showed that many NPS were unstable in biological matrices during storage even when frozen, and proved the possibility of the decomposition of some of these compounds. The same authors also investigated the stability of
NPS during repeated thawing and freezing cycles. Therefore, the conditions of both sample transport after collection and storage are crucial to obtaining reliable data from the analysis, and it is advised that the samples should be analyzed as soon as possible after delivery to the laboratory. The stability of extracts in GC autosamplers while waiting for injection is also a key factor affecting the final results because GC autosamplers are typically not cooled. This issue is of significant importance in view of the limited data available on this topic due to the large number of NPS.

Based on the above, in this study, only the stability of the samples in the GC autosampler was verified. The stabilities were measured at three concentration levels by analysis of QC samples $(n=3)$ left in a GC autosampler for 12 and $24 \mathrm{~h}$, and the stabilities were calculated as the accuracy of these measurements.

\section{Results and discussion}

The number of NPS is still growing in many countries, and therefore, the analysis of these substances in biological samples has been a challenge for both clinical and forensic laboratories. The ideal method would be rapid, simple, sensitive, specific, inexpensive, and able to detect a large number of compounds in one analytical run. Moreover, a simple and fast sample preparation procedure is necessary so that the chromatographic methods can replace immunoassays, and proper data interpretation should be ensured.

\section{GC-MS/MS optimization}

To achieve high sensitivity and selectivity in the developed procedure, the MS/MS parameters were optimized. MRM transitions were evaluated using the Shimadzu MRM Optimization Tool software. This software automatically fragments ions using various voltages and selects the most intense ion fragments and optimizes the collision energy for each transition. For this purpose, the derivatized mixture of analytes and the IS $(2 \mu \mathrm{L})$ at a concentration of $25 \mu \mathrm{g} /$ $\mathrm{mL}$ was injected into the GC-MS/MS system in full scan mode in the range of $30-500 \mathrm{~m} / \mathrm{z}$ using standard equipment parameters; i.e., the temperatures of the injection port (split mode 10:1), MS transfer line and ion source were 260, 285, and $230{ }^{\circ} \mathrm{C}$, respectively. The oven temperature gradient program during this experiment was as follows: hold at an initial temperature of $50{ }^{\circ} \mathrm{C}$ for $1 \mathrm{~min}$, ramp to $300{ }^{\circ} \mathrm{C}$ at a gradient of $10{ }^{\circ} \mathrm{C} / \mathrm{min}$, and then hold at $300{ }^{\circ} \mathrm{C}$ for $5 \mathrm{~min}$. 
Then, two of the most abundant ions were chosen for fragmentation with variable CEs in the range of $3-42 \mathrm{~V}(3 \mathrm{~V}$ step) during examination of the product ions, and the two most appropriate MRM transitions based on abundance were chosen for further analysis. In the case of analytes with the same RTs, separate MRM optimization experiments were performed. Then, the chromatographic conditions, such as the injector and initial and final column temperatures, as well as the column temperature ramp rate and carrier gas flow rate, were optimized to obtain high sensitivity and good separation of the analytes. In the presented method, chromatographic separation of all the analytes was not achieved. Although it is very difficult to obtain chromatographic separation in an analysis allowing the determination of many compounds during one analytical cycle, specific and selective MRM can be used as a virtual separation method. In the present study, two transitions were chosen for all analytes and ISs. However, some analytes (structural isomers of methylmethcathinone, 2-MMC and 3-MMC, and chlorinated methcathinones 3-CMC and 4-CMC) had close RTs (for 2-MMC and 3-MMC: 11.31 and $11.35 \mathrm{~min}$, respectively, and for 4-CMC and 3-CMC: 12.41 and $12.47 \mathrm{~min}$, respectively) and shared the same transitions (Fig. 1). The identification of these compounds was facilitated by the use of ISs and the calculation of their relative RTs, which overcome potential variations in the RTs. For these isomeric compounds, the developed method is limited to screening, and quantification is only possible when only one of these analytes is present in the sample. On the other hand, using the developed method, it was not possible to distinguish isomers 3- and 4-CEC because these compounds have the same MRMs and RTs. Therefore, other methods (e.g., methods based on LC-MS/ MS) should be used to differentiate and quantify these analytes. For other analytes, either different RTs or transitions were obtained, which allowed quantification. Similar challenges in the separation of NPS isomers have been observed in other studies [8].

The selection of the proper ion source temperature is also a key factor in achieving a high sensitivity and $\mathrm{S} / \mathrm{N}$ ratio in GC-MS analyses. During this study, temperatures ranging from 200 to $260{ }^{\circ} \mathrm{C}$ (at $10-^{\circ} \mathrm{C}$ intervals) were tested, and the results in terms of the peak intensities for all analytes and the ISs were analyzed. The best temperature $\left(250{ }^{\circ} \mathrm{C}\right)$, i.e., that which provides the highest sensitivity, was chosen for quantification. The use of splitless injection mode for 0.5 min provided a high $\mathrm{S} / \mathrm{N}$ ratio and good peak shapes with no additional signals from the interferences by impurities in blood samples or from side-products of the derivatization process. However, some problems were observed during the selection of the solvent to dissolve the sample after derivatization (before injection), which was critical for the performance of the assay and influenced the peaks' shape as well as chromatographic separation. Ethyl acetate is typically used, but in splitless mode, fronting peaks were observed for most analytes (when split mode was used during MRM optimization, this undesirable feature was not observed). Therefore, we tested other solvents commonly used in GC analyses, i.e., $\mathrm{MeOH}$, hexane, acetonitrile (ACN), and DCM. DCM was the only solvent that provided good peak shapes, while for $\mathrm{ACN}$ and $\mathrm{MeOH}$, additional peaks were observed (probably from side-products of the derivatization or impurities eluted from the GC liner or column). This situation may be explained by using initial column temperature of $50{ }^{\circ} \mathrm{C}$ which was below boiling point of $\mathrm{ACN}, \mathrm{MeOH}$, and hexane. Therefore, these solvents may condense on the column inlet and trap analytes. Although DCM is a very volatile solvent that may lead to the evaporation of samples waiting in a GC autosampler, this solvent was chosen for analysis. To limit the influence of sample evaporation in the GC autosampler, the IS calibration was used.

To summarize, the developed and optimized GC-MS/ MS-based method includes two transitions for each substance, a quantifier and a qualifier (a total of 94 transitions for 45 drugs and 2 ISs), a total method run-time of approximately $32 \mathrm{~min}$, and a data acquisition time of $22 \mathrm{~min}$. Sixteen time segments were automatically applied by the MRM Optimization Tool software, which enabled the monitoring of transitions only in the ranges of the expected RT of each compound. This allowed us to obtain a maximum dwell time for each analyte with a loop time of $0.25 \mathrm{~s}$, which provided
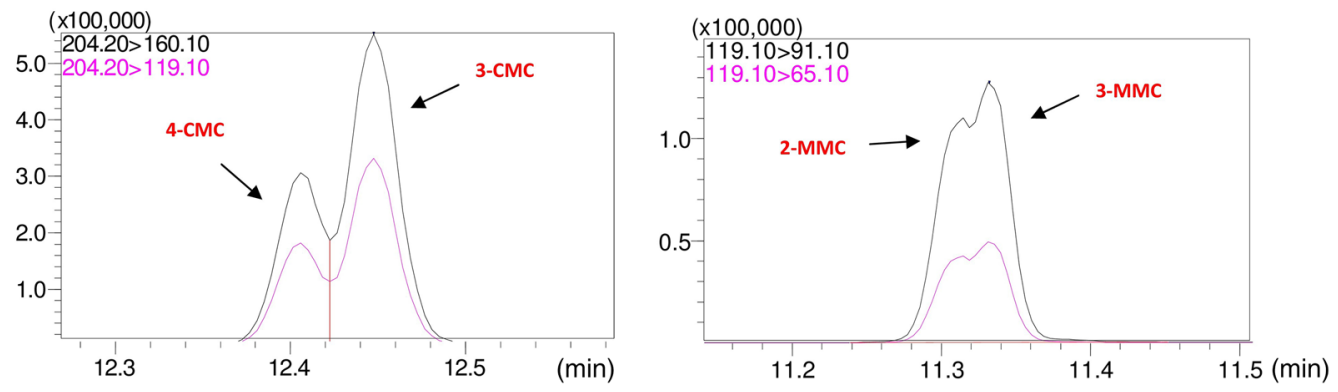

Fig. 1 Multiple reaction monitoring (MRM) chromatograms of unresolved isomers of NPS included in the study 
a better sensitivity and $\mathrm{S} / \mathrm{N}$ ratio. Thus, background noise and matrix interferences were also excluded, improving the sensitivity of the method. These MS conditions ensured the adequate number of points to define the proper shape of each chromatographic peak. The list of compounds analysed in the study (in order of RT) with their corresponding RTs, transitions and CEs is presented in Table 1. A chromatogram of a sample of blood spiked with all the analytes of interest at a concentration of $5 \mathrm{ng} / \mathrm{mL}$ is presented in Fig. 2 .

\section{Extraction and derivatization}

The analysis of ATSs and cathinones by GC generally requires the use of derivatizing reagents. Based on literature data [25], PFPA, which is recognized as the best acylation reagent for ATSs and cathinones, was used in our study. However, the authors of the above article investigated only a few cathinones; therefore, the derivatization temperature and time were optimized in our study (data not shown). Not all analyzed compounds have been structurally derivatized; only compounds that include a free $-\mathrm{NH}$ or $-\mathrm{NH}_{2}$ group can be derivatized. For example, cathinones containing pyrrolidinophenone units cannot be derivatized. However, for these analytes, proper peak shape and sensitivity were obtained in our study (but they had higher LOQs, as described further).
The details of the derivatization process for all the analyzed compounds are presented in Table 1.

LLE was chosen as the extraction technique because of its many advantages, including its simplicity and minimal time requirements, which make it ideal for routine forensic toxicology analyses. Various organic solvents, including ethyl acetate [19], 1-chlorobutane [26], and mixtures of ethyl acetate with hexane [27] have been proposed in the literature for the extraction of ATSs and cathinones from biological samples. In our study, ethyl acetate and 1-chlorobutane were tested, and higher recoveries and lower influence from the matrix (occurrence of additional peaks in the chromatogram as interferences in RTs of analytes) were obtained when using ethyl acetate (Fig. S1 in the supplementary material). As can be seen, in case of 1-chlorobutane, additional peaks as interferences co-extracted from the matrix were recognized at RTs of a few analytes. However, the $\mathrm{pH}$ of the sample was crucial to analyte migration from the aqueous environment (blood) to the organic solvent. The pKa values of most of the compounds of interest are higher than 9; therefore, alkalization of the sample before extraction is required. Typically, the addition of carbonate buffer ( $\mathrm{pH} 12)$ [26] is suggested for this purpose. However, in that study, LC-MS/MS was utilized as the detection technique, and we found that when using GC-MS/MS and derivatization with PFPA, a carbonate buffer led to the extraction of many
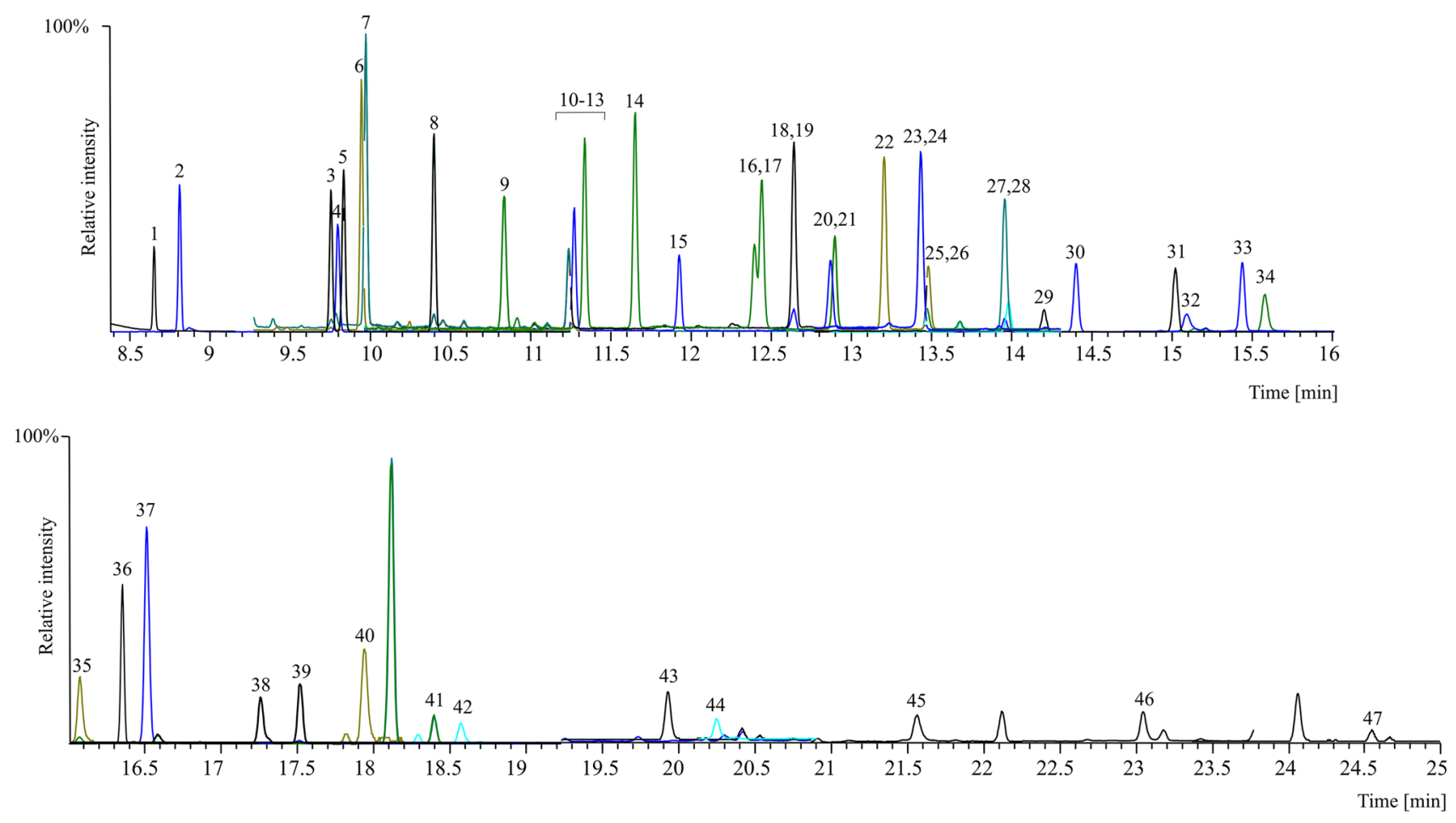

Fig. 2 MRM chromatogram of the blood sample spiked with target analytes at the concentration of $5 \mathrm{ng} / \mathrm{mL}$ (the numbers assigned to the peaks correspond to those of compounds listed in Table 1) 
impurities from the blood samples. Therefore, in this study, $\mathrm{NaOH}$ solution $(0.1 \mathrm{M})$ was used to alkalize the samples, similarly to our earlier research [1].

Another problem associated with the analysis of synthetic cathinones using the GC technique is thermal instability of some of these compounds in the injection port [28]. In our study, most of analytes were in a derivatized form during GC analysis which makes them more volatile and more thermally stable. The obtained validation parameters were satisfactory (especially low LODs and LOQs) as described below, which made our method proper for NPS analysis. We also used matrix-matched IS calibration, which reduced problems associated with extraction, matrix, and stability.

\section{Method validation}

The developed method was validated for all analyzed compounds. The validation data are summarized in Tables 2, 3 and Table S2.

Various MS responses were obtained for the analytes. Therefore, different ranges of calibration curves were used. For most analytes, $1-250 \mathrm{ng} / \mathrm{mL}$ was used (eight-point calibration curves). The exceptions were MDPBP, MDPV, and naphyrone, which used a range of $2.5-250 \mathrm{ng} / \mathrm{mL}$ (sevenpoint calibration curves). Weighted least square regression was applied to the calibration curves of most analytes to improve the accuracy, especially at the low ends of their concentration ranges. The weighted linear regression model is now becoming rather common despite its additional complexity in cases of heteroscedasticity, and it is the method of choice for some authors [29]. Six weighting factors, namely, $1 / x, 1 / x^{2}, 1 / \sqrt{x}, 1 / y, 1 / y^{2}$, and $1 / \sqrt{y}$, were tested. The one with the lowest sum of relative errors and the highest accuracy was selected for the analytes and was used for evaluation of the linearity and the repeatability of the method. The method was shown to be linear within the tested ranges. The correlation coefficients ( $r$ values) were all above 0.9900 .

The LODs of all the analytes were estimated, and the values ranged from 0.02 to $0.72 \mathrm{ng} / \mathrm{mL}$. The LOQs were assumed to be the lowest point in the linear range of the calibration curves and were $1 \mathrm{ng} / \mathrm{mL}$ for most analytes and $2.5 \mathrm{ng} / \mathrm{mL}$ for MDPBP, MDPV, and naphyrone. The LODs were always below the first calibration levels.

No interfering peaks that obstruct the identification and quantification of the analytes were observed in the drugfree blood samples taken from 20 subjects (both ante- and postmortem). Therefore, it can be concluded that neither endogenous matrix constituents nor any of the reagents added during the extraction or derivatization steps interfered with the tested compounds. Carry-over effects were not observed. Therefore, by using MRM mode, any interferences that may be present could be filtered out, and the transitions chosen for each compound were sufficient for selectively identifying the correct compound. These experiments proved the selectivity of the developed procedure for the studied analytes.

The results obtained during the matrix effects experiments are listed in Table S2. Negative values indicate suppression, while positive values indicate enhancement of the detector signal. Indeed, matrix effects in the range of -20 to $20 \%$ are considered permissible and can be neglected, while when stronger effects are observed, matrix-matched calibrators must be used [30]. Based on the obtained results, significant matrix effects were observed for 11 of the analytes. Therefore, matrix-matched calibration, instead of external calibration, was used in the study. Moreover, to compensate for the instability of the detector signal during analysis and the loss of analytes in the extraction-derivatization procedure (correction of the recoveries), IS calibration was performed. In the present study, only deuterated compounds were used as ISs to avoid the potential overestimation of the IS signal that can occur when using a therapeutic drug as the IS (they can be co-extracted from real samples).

The accuracy and precision values (both for intra- and inter-assay tests) were within the acceptable interval of $\pm 15 \%$ for MQC and HQC and $\pm 20 \%$ for LQC. The results showed that the investigated method is sufficiently accurate and precise. Using the developed procedure, recoveries in the range of $83.2-105.8 \%$ were obtained and were reproducible (the maximum standard deviation was $12.2 \%$ ). These values meet the established criteria (80-120\%).

The stability studies showed that storage of the extracts in the GC autosampler at room temperature led to losses of the analytes (maximum losses of 9.8 and $14 \%$ after 12 and $24 \mathrm{~h}$, respectively, based on the accuracy). Such values are within the limits of acceptable errors for bioanalytical methods; the analytes are stable in the autosampler for $24 \mathrm{~h}$. However, Mercieca et al. [3] showed the instability of some NPS injected after $36 \mathrm{~h}$ of storage at room temperature (43\% average loss of analytes). Therefore, extracts should be analyzed within $24 \mathrm{~h}$. However, in view of the analysis time (32 $\mathrm{min}$ ), it is possible to analyze 45 samples in $24 \mathrm{~h}$ using the proposed procedure. For many compounds, their stability in a GC autosampler was verified for the first time, because of the smaller number of articles concerning the use of GC for NPS analysis.

\section{Comparison with other analytical procedures}

The concentrations of NPS in blood samples after their use typically range from a few $\mathrm{ng} / \mathrm{mL}$ to hundreds of $\mathrm{ng} / \mathrm{mL}$ [31]. Therefore, it is very important that each new method developed for NPS analysis should be very sensitive and allows the detection of such substances over a wide concentration range. 
Table 2 Quantification and calibration data

\begin{tabular}{|c|c|c|c|c|c|c|c|c|}
\hline \multirow[t]{2}{*}{ Compound name } & \multirow{2}{*}{$\begin{array}{l}\text { Calibration curve range (ng/ } \\
\mathrm{ml} ; 7 \text { or } 8 \text { points; } n=3 \text { ) }\end{array}$} & \multirow{2}{*}{$\begin{array}{l}\text { Weighting } \\
\text { factor }\end{array}$} & \multicolumn{6}{|c|}{ Calibration curve } \\
\hline & & & $a$ & $b$ & $S_{a}$ & $S_{b}$ & $r$ & $\begin{array}{l}\text { LOD } \\
(\mathrm{ng} / \mathrm{ml})\end{array}$ \\
\hline Amphetamine & $1-250$ & $1 / x$ & 0.0232 & 0.004 & 0.0060 & 0.096 & 0.9996 & 0.11 \\
\hline Phentermine & $1-250$ & $1 / x^{2}$ & 0.0384 & 0.001 & 0.0084 & 0.022 & 0.9997 & 0.07 \\
\hline Ephedrine & $1-250$ & $1 / x$ & 0.063 & 0.009 & 0.012 & 0.019 & 0.9992 & 0.04 \\
\hline Methamphetamine & $1-250$ & - & 0.06019 & 0.028 & 0.00063 & 0.061 & 0.9992 & 0.05 \\
\hline Cathinone & $1-250$ & $1 / x$ & 0.058 & 0.02 & 0.011 & 0.17 & 0.9995 & 0.02 \\
\hline Pseudoephedrine & $1-250$ & - & 0.08230 & 0.016 & 0.00067 & 0.065 & 0.9995 & 0.05 \\
\hline 4-MMA & $1-250$ & - & 0.0412 & 0.0017 & 0.0011 & 0.0054 & 0.9996 & 0.18 \\
\hline Ethcathinone & $1-250$ & $1 / x$ & 0.0189 & -0.007 & 0.0035 & 0.056 & 0.9995 & 0.10 \\
\hline PMA & $1-250$ & $1 / x$ & 0.0529 & -0.02 & 0.0097 & 0.15 & 0.9993 & 0.09 \\
\hline 2-MMC & $1-250$ & $1 / x$ & 0.04991 & -0.0211 & 0.00014 & 0.0012 & 0.9995 & 0.04 \\
\hline 3-MMC & $1-250$ & $1 / x$ & 0.0432 & -0.02 & 0.0079 & 0.13 & 0.9996 & 0.04 \\
\hline 4-MMC & $1-250$ & - & 0.05342 & -0.037 & 0.00045 & 0.044 & 0.9995 & 0.04 \\
\hline Pentedrone & $1-250$ & - & 0.01762 & -0.001 & 0.00019 & 0.018 & 0.9992 & 0.07 \\
\hline 4-CMC & $1-250$ & $1 / x$ & 0.03189 & -0.022 & 0.00011 & 0.012 & 0.9991 & 0.10 \\
\hline 3-CMC & $1-250$ & $1 / x$ & 0.0246 & -0.010 & 0.0045 & 0.072 & 0.9995 & 0.07 \\
\hline MDA & $1-250$ & $1 / x$ & 0.059 & -0.03 & 0.011 & 0.18 & 0.9989 & 0.07 \\
\hline 4-MEC & $1-250$ & - & 0.05007 & -0.043 & 0.00050 & 0.048 & 0.9993 & 0.04 \\
\hline PMMA & $1-250$ & - & 0.06421 & 0.0054 & 0.00041 & 0.0013 & 0.9989 & 0.09 \\
\hline 4-EMC & $1-250$ & $1 / x$ & 0.0255 & -0.011 & 0.0047 & 0.075 & 0.9992 & 0.09 \\
\hline 3,4-DMMC & $1-250$ & - & 0.04669 & -0.021 & 0.00048 & 0.047 & 0.9993 & 0.10 \\
\hline 4-MPD & $1-250$ & - & 0.05133 & -0.028 & 0.00059 & 0.057 & 0.9991 & 0.03 \\
\hline$N$-Propylpentedrone & $1-250$ & - & 0.007309 & -0.0027 & 0.000083 & 0.0081 & 0.9988 & 0.16 \\
\hline 3-CEC & $1-250$ & $1 / x$ & 0.0190 & -0.009 & 0.0035 & 0.056 & 0.9991 & 0.11 \\
\hline 4-CEC & $1-250$ & $1 / x$ & 0.0192 & -0.0041 & 0.0015 & 0.0043 & 0.9991 & 0.10 \\
\hline Hex-en & $1-250$ & - & 0.01608 & -0.005 & 0.00016 & 0.015 & 0.9993 & 0.10 \\
\hline Methedrone & $1-250$ & - & 0.04057 & -0.013 & 0.00032 & 0.031 & 0.9995 & 0.11 \\
\hline 4-CPD & $1-250$ & $1 / x$ & 0.00916 & -0.003 & 0.00089 & 0.014 & 0.9989 & 0.12 \\
\hline MDMA & $1-250$ & $1 / x$ & 0.0432 & -0.018 & 0.0043 & 0.068 & 0.9995 & 0.16 \\
\hline MDEA & $1-250$ & $1 / x$ & 0.0415 & -0.016 & 0.0041 & 0.066 & 0.9995 & 0.14 \\
\hline$\alpha-\mathrm{PVP}$ & $1-250$ & $1 / x$ & 0.01002 & -0.006 & 0.00098 & 0.016 & 0.9995 & 0.31 \\
\hline Methylone & $1-250$ & $1 / x$ & 0.0311 & 0.0054 & 0.0012 & 0.0012 & 0.9971 & 0.11 \\
\hline$\alpha-\mathrm{PiHP}$ & $1-250$ & $1 / x^{2}$ & 0.0149 & -0.0028 & 0.0017 & 0.0043 & 0.9994 & 0.32 \\
\hline 4-F-PHP & $1-250$ & $1 / x$ & 0.0102 & -0.005 & 0.0010 & 0.016 & 0.9998 & 0.21 \\
\hline Butylone & $1-250$ & $1 / x$ & 0.0274 & -0.007 & 0.0027 & 0.043 & 0.9994 & 0.16 \\
\hline$\alpha$-PHP & $1-250$ & $1 / x$ & 0.00973 & -0.005 & 0.00096 & 0.015 & 0.9914 & 0.31 \\
\hline Eutylone & $1-250$ & - & 0.02330 & -0.007 & 0.00012 & 0.011 & 0.9998 & 0.11 \\
\hline Pentylone & $1-250$ & - & 0.03248 & -0.015 & 0.00014 & 0.014 & 0.9998 & 0.12 \\
\hline 4-Cl- $\alpha-\mathrm{PVP}$ & $1-250$ & $1 / x$ & 0.00785 & -0.004 & 0.00078 & 0.012 & 0.9993 & 0.19 \\
\hline Ephylone & $1-250$ & $1 / x$ & 0.0209 & -0.01 & 0.0021 & 0.033 & 0.9998 & 0.18 \\
\hline PV4 (MPHP) & $1-250$ & $1 / x^{2}$ & 0.0096 & 0.0001 & 0.0011 & 0.0029 & 0.9989 & 0.33 \\
\hline PV9 & $1-250$ & $1 / x^{2}$ & 0.00802 & -0.0031 & 0.00088 & 0.0023 & 0.9982 & 0.32 \\
\hline MDPBP & $2.5-250$ & - & 0.007797 & -0.0005 & 0.000076 & 0.0079 & 0.9914 & 0.72 \\
\hline MDPV & $2.5-250$ & $1 / x$ & 0.00942 & 0.0101 & 0.00012 & 0.0030 & 0.9902 & 0.68 \\
\hline 3,4-MDPHP & $1-250$ & $1 / x$ & 0.0154 & -0.008 & 0.0015 & 0.024 & 0.9917 & 0.29 \\
\hline Naphyrone & $2.5-250$ & $1 / x^{2}$ & 0.00726 & -0.00113 & 0.00017 & 0.00095 & 0.9908 & 0.67 \\
\hline
\end{tabular}

The compounds are aligned according to the retention times (see Table 1)

$L O D$ limit of detection, $r$ correlation coefficient, $a$ slope, $b$ intercept with vertical axis, $S_{\mathrm{a}}$ standard deviation of slope, $S_{\mathrm{b}}$ standard deviation of intercept 
Table 3 Data on accuracies, precisions, and recoveries for the studied analytes

\begin{tabular}{|c|c|c|c|c|c|c|}
\hline \multirow[t]{2}{*}{ Analyte } & \multirow[t]{2}{*}{$C$} & \multicolumn{3}{|c|}{ Intraday assay } & \multirow[t]{2}{*}{ Interday assay } & \multirow{2}{*}{$\begin{array}{l}\text { Recovery } \\
(\text { mean } \pm S D)\end{array}$} \\
\hline & & Day 1 & Day 2 & Day 3 & & \\
\hline \multirow[t]{3}{*}{ Amphetamine } & 2.5 & $91.3(1.2)$ & 99.7 (4.3) & $95.3(3.5)$ & $95.4(4.7)$ & $94.5 \pm 2.9$ \\
\hline & 25 & $102(0.9)$ & $103(0.1)$ & $102(2.4)$ & $102(1.3)$ & $96.9 \pm 3.4$ \\
\hline & 200 & $102(0.5)$ & $104(2.3)$ & $103(1.6)$ & $103(0.0)$ & $96.2 \pm 1.3$ \\
\hline \multirow[t]{3}{*}{ Phentermine } & 2.5 & $95.6(1.6)$ & $111(5.2)$ & $107(1.2)$ & $105(7.3)$ & $88.8 \pm 12.2$ \\
\hline & 25 & $104(6.4)$ & $114(0.1)$ & $106(0.5)$ & $108(5.1)$ & $98.3 \pm 6.3$ \\
\hline & 200 & $93.5(0.5)$ & $96.9(3.0)$ & $97.8(3.7)$ & $96.0(0.0)$ & $99.4 \pm 3.4$ \\
\hline \multirow[t]{3}{*}{ Ephedrine } & 2.5 & $97.9(7.1)$ & $92.7(3.1)$ & $96.5(6.4)$ & $95.7(5.2)$ & $92.6 \pm 2.5$ \\
\hline & 25 & $105(2.3)$ & $93.1(0.8)$ & $99.9(3.1)$ & $99.0(5.5)$ & $93.8 \pm 2.6$ \\
\hline & 200 & $96.3(2.8)$ & $94.5(8.6)$ & $97.6(1.9)$ & $96.0(0.0)$ & $93.6 \pm 8.6$ \\
\hline \multirow[t]{3}{*}{ Methamphetamine } & 2.5 & $99.7(1.1)$ & $95.9(6.0)$ & $94.8(3.6)$ & $96.8(3.9)$ & $93.6 \pm 2.3$ \\
\hline & 25 & $96.9(1.3)$ & $93.4(6.0)$ & $96.7(2.4)$ & $95.0(2.1)$ & $96.3 \pm 0.4$ \\
\hline & 200 & $99.6(1.6)$ & $97.5(4.1)$ & $97.3(1.8)$ & $98.0(0.0)$ & $96.1 \pm 0.1$ \\
\hline \multirow[t]{3}{*}{ Cathinone } & 2.5 & $95.8(1.1)$ & $97.5(0.5)$ & $98.3(2.8)$ & $97.2(1.8)$ & $88.5 \pm 3.6$ \\
\hline & 25 & $93.6(0.7)$ & $94.8(1.1)$ & $95.1(1.9)$ & $95.0(1.3)$ & $85.9 \pm 3.5$ \\
\hline & 200 & $101(0.1)$ & $94.1(2.3)$ & $97.0(0.6)$ & $97.0(0.0)$ & $90.8 \pm 4.4$ \\
\hline \multirow[t]{3}{*}{ Pseudoephedrine } & 2.5 & $94.7(5.3)$ & $95.1(8.1)$ & $93.3(5.0)$ & $94.4(5.0)$ & $87.8 \pm 4.3$ \\
\hline & 25 & $101(2.6)$ & $88.5(1.5)$ & $92.1(0.3)$ & $94.0(6.3)$ & $83.2 \pm 0.4$ \\
\hline & 200 & $99.6(2.2)$ & $94.5(1.3)$ & $94.3(0.3)$ & $96.0(0.0)$ & $94.0 \pm 9.3$ \\
\hline \multirow[t]{3}{*}{ 4-MMA } & 2.5 & $104(4.2)$ & $96.5(5.2)$ & $95.2(3.9)$ & $98.7(5.0)$ & $92.0 \pm 2.1$ \\
\hline & 25 & $108(3.6)$ & $101(2.9)$ & $97.9(2.1)$ & $102(5.0)$ & $96.1 \pm 3.3$ \\
\hline & 200 & $99.5(2.0)$ & $105(4.1)$ & $102(4.1)$ & $102(2.8)$ & $94.4 \pm 2.9$ \\
\hline \multirow[t]{3}{*}{ Ethcathinone } & 2.5 & $96.3(7.7)$ & $96.5(1.3)$ & $98.6(5.9)$ & $97.1(4.5)$ & $97.5 \pm 3.9$ \\
\hline & 25 & $94.1(0.8)$ & $91.5(0.6)$ & $91.5(2.4)$ & $92.0(1.9)$ & $90.5 \pm 5.2$ \\
\hline & 200 & $100(0.5)$ & $92.4(1.7)$ & $96.1(0.9)$ & $96.0(0.0)$ & $95.4 \pm 4.3$ \\
\hline \multirow[t]{3}{*}{ PMA } & 2.5 & $103(9.0)$ & $107(1.1)$ & $98.5(2.6)$ & $103(5.5)$ & $94.3 \pm 4.4$ \\
\hline & 25 & $97.2(7.2)$ & $92.2(1.8)$ & $94.9(3.5)$ & $95.0(4.4)$ & $98.1 \pm 2.2$ \\
\hline & 200 & $101(2.6)$ & $97.9(0.0)$ & $97.0(0.0)$ & $99.0(0.0)$ & $97.4 \pm 1.6$ \\
\hline \multirow[t]{3}{*}{ 2-MMC } & 2.5 & $105(4.1)$ & $97.5(5.6)$ & $106(2.1)$ & $103(4.5)$ & $92.3 \pm 4.6$ \\
\hline & 25 & $95.1(2.9)$ & $98.3(3.3)$ & $92.6(4.7)$ & $95.3(3.0)$ & $95.1 \pm 3.1$ \\
\hline & 200 & $100(6.4)$ & $95.8(2.1)$ & $101(4.2)$ & $99.0(2.9)$ & $105.8 \pm 3.9$ \\
\hline \multirow[t]{3}{*}{ 3-MMC } & 2.5 & $96.9(4.7)$ & $98.9(0.8)$ & $99.8(0.4)$ & $98.5(2.5)$ & $89.5 \pm 0.9$ \\
\hline & 25 & $94.1(0.1)$ & $92.4(1.3)$ & $90.2(1.3)$ & $92.0(2.0)$ & $91.0 \pm 4.6$ \\
\hline & 200 & $101(0.3)$ & $92.5(1.5)$ & $94.9(1.4)$ & $96.0(0.0)$ & $95.1 \pm 3.6$ \\
\hline \multirow[t]{3}{*}{ 4-MMC } & 2.5 & $105(0.2)$ & $102(0.0)$ & $104(0.5)$ & $104(1.2)$ & $93.7 \pm 1.8$ \\
\hline & 25 & $95.0(0.1)$ & $92.2(0.8)$ & $93.4(1.7)$ & $94.0(1.6)$ & $92.8 \pm 5.2$ \\
\hline & 200 & $99.7(0.5)$ & $99.6(0.7)$ & $102(1.2)$ & $100(0.0)$ & $95.6 \pm 2.5$ \\
\hline \multirow[t]{3}{*}{ Pentedrone } & 2.5 & $94.6(7.2)$ & $101(5.1)$ & 105 (8.7) & $100(7.1)$ & $91.0 \pm 2.8$ \\
\hline & 25 & $94.3(1.5)$ & $94.2(2.0)$ & 93.7 (3.9) & $94.0(2.1)$ & $95.1 \pm 4.8$ \\
\hline & 200 & $99.7(1.5)$ & $93.8(1.2)$ & $95.9(1.2)$ & $96.0(0.0)$ & $97.4 \pm 2.1$ \\
\hline \multirow[t]{3}{*}{ 4-CMC } & 2.5 & $93.1(5.4)$ & $96.5(4.9)$ & $91.3(5.5)$ & $93.6(2.8)$ & $94.5 \pm 3.3$ \\
\hline & 25 & $94.8(3.9)$ & $95.8(3.1)$ & $92.5(2.1)$ & $94.4(1.8)$ & $93.1 \pm 3.9$ \\
\hline & 200 & $98.2(2.2)$ & $95.7(3.9)$ & 96.4 (1.9) & $96.8(1.3)$ & $91.2 \pm 2.8$ \\
\hline \multirow[t]{3}{*}{ 3-CMC } & 2.5 & $98.2(6.7)$ & $97.6(0.5)$ & $99.0(0.5)$ & $98.3(3.1)$ & $93.3 \pm 3.8$ \\
\hline & 25 & $93.5(0.9)$ & $90.8(1.8)$ & $90.6(2.0)$ & $92.0(2.0)$ & $88.7 \pm 5.1$ \\
\hline & 200 & $101(0.0)$ & $98.5(1.9)$ & 95.7 (2.9) & $98.0(0.0)$ & $93.2 \pm 3.9$ \\
\hline \multirow[t]{3}{*}{ MDA } & 2.5 & $101(7.7)$ & $96.8(7.7)$ & $96.8(2.3)$ & $98.2(5.5)$ & $97.4 \pm 2.9$ \\
\hline & 25 & $95.8(6.5)$ & $92.4(3.1)$ & 90.1 (1.9) & $93.0(4.4)$ & $97.4 \pm 3.7$ \\
\hline & 200 & $101(4.1)$ & $103(2.7)$ & $102(0.9)$ & $102(0.0)$ & $95.0 \pm 5.1$ \\
\hline
\end{tabular}


Table 3 (continued)

\begin{tabular}{|c|c|c|c|c|c|c|}
\hline \multirow[t]{2}{*}{ Analyte } & \multirow[t]{2}{*}{$C$} & \multicolumn{3}{|c|}{ Intraday assay } & \multirow[t]{2}{*}{ Interday assay } & \multirow{2}{*}{$\begin{array}{l}\text { Recovery } \\
(\text { mean } \pm \mathrm{SD})\end{array}$} \\
\hline & & Day 1 & Day 2 & Day 3 & & \\
\hline \multirow[t]{3}{*}{ 4-MEC } & 2.5 & $110(4.1)$ & 101 (1.6) & $111(5.0)$ & $107(5.5)$ & $97.0 \pm 2.6$ \\
\hline & 25 & $93.7(2.7)$ & $92.4(10.0)$ & $94.0(2.8)$ & $93.0(4.8)$ & $94.7 \pm 6.2$ \\
\hline & 200 & $99.7(1.5)$ & $97.0(4.5)$ & $94.6(1.8)$ & $97.0(0.0)$ & $96.6 \pm 1.9$ \\
\hline \multirow[t]{3}{*}{ PMMA } & 2.5 & $92.5(6.4)$ & $90.9(5.5)$ & $95.1(3.9)$ & $92.8(2.3)$ & $91.3 \pm 5.2$ \\
\hline & 25 & $95.1(3.2)$ & $92.9(3.9)$ & $96.2(4.9)$ & $94.7(1.8)$ & $92.9 \pm 4.8$ \\
\hline & 200 & $96.3(2.1)$ & $94.1(2.5)$ & $97.5(2.9)$ & $96.0(1.8)$ & $96.1 \pm 2.9$ \\
\hline \multirow[t]{3}{*}{ 4-EMC } & 2.5 & $96.3(8.4)$ & $94.9(1.2)$ & $94.1(2.1)$ & $95.1(4.1)$ & $96.4 \pm 3.6$ \\
\hline & 25 & $94.9(2.1)$ & $88.7(1.1)$ & $95.0(4.8)$ & $93.0(4.3)$ & $96.7 \pm 5.5$ \\
\hline & 200 & $101(1.5)$ & $99.5(2.4)$ & $99.1(2.7)$ & $100(0.0)$ & $96.6 \pm 1.9$ \\
\hline \multirow[t]{3}{*}{ 3,4-DMMC } & 2.5 & $100(7.7)$ & $95.2(0.6)$ & $96.6(1.5)$ & $97.3(4.3)$ & $94.2 \pm 3.7$ \\
\hline & 25 & $95.3(3.2)$ & $92.7(0.8)$ & $93.1(1.3)$ & $94.0(2.1)$ & $96.3 \pm 5.0$ \\
\hline & 200 & $99.5(0.1)$ & $92.5(0.3)$ & $95.3(2.6)$ & $96.0(0.0)$ & $96.4 \pm 1.5$ \\
\hline \multirow[t]{3}{*}{ 4-MPD } & 2.5 & $114(5.8)$ & $105(4.4)$ & $101(0.8)$ & $107(6.3)$ & $95.1 \pm 1.6$ \\
\hline & 25 & $94.0(2.4)$ & $89.3(0.0)$ & $91.6(3.1)$ & $92.0(2.9)$ & $94.6 \pm 7.3$ \\
\hline & 200 & $99.7(2.5)$ & $96.6(1.2)$ & $96.8(0.2)$ & $98.0(0.0)$ & $96.9 \pm 2.3$ \\
\hline \multirow[t]{3}{*}{$N$-Propylpentedrone } & 2.5 & $101(10.3)$ & $95.2(0.1)$ & $95.2(2.1)$ & $97.0(5.6)$ & $91.6 \pm 2.1$ \\
\hline & 25 & $94.5(4.4)$ & 89.1 (1.6) & $95.7(2.5)$ & $93.0(4.1)$ & $92.3 \pm 6.6$ \\
\hline & 200 & $99.3(0.0)$ & $94.8(1.2)$ & $96.1(0.5)$ & $97.0(0.0)$ & $95.2 \pm 2.8$ \\
\hline \multirow[t]{3}{*}{ 3-CEC } & 2.5 & $101(11.2)$ & $91.5(1.0)$ & $92.5(1.5)$ & $94.9(7.2)$ & $95.1 \pm 5.9$ \\
\hline & 25 & $91.8(3.3)$ & $86.1(0.9)$ & $88.6(4.5)$ & $89.0(3.8)$ & $93.4 \pm 7.2$ \\
\hline & 200 & $101(2.1)$ & 103 (1.6) & $99.3(6.8)$ & $101(0.0)$ & $96.7 \pm 2.9$ \\
\hline \multirow[t]{3}{*}{ 4-CEC } & 2.5 & $105(5.5)$ & $97.3(4.2)$ & 105 (4.6) & $102(4.3)$ & $104.2 \pm 5.2$ \\
\hline & 25 & $95.4(6.1)$ & $99.1(5.2)$ & $103(4.3)$ & $99.1(3.8)$ & $96.5 \pm 2.5$ \\
\hline & 200 & $93.5(3.3)$ & $99.1(3.9)$ & $101(5.2)$ & $98.0(4.1)$ & $99.1 \pm 8.1$ \\
\hline \multirow[t]{3}{*}{ Methedrone } & 2.5 & $99.6(10.2)$ & $93.8(0.1)$ & $96.9(4.0)$ & $96.8(5.7)$ & $93.4 \pm 9.4$ \\
\hline & 25 & $94.1(3.4)$ & $89.0(0.2)$ & $90.5(2.1)$ & $91.0(3.2)$ & $93.7 \pm 7.0$ \\
\hline & 200 & $99.5(0.4)$ & $97.3(1.4)$ & $97.6(1.4)$ & $98.0(0.0)$ & $94.7 \pm 2.0$ \\
\hline \multirow[t]{3}{*}{ Hex-en } & 2.5 & $99.3(8.0)$ & $92.2(0.1)$ & $93.5(1.8)$ & $95.0(5.2)$ & $93.6 \pm 2.7$ \\
\hline & 25 & $95.6(2.7)$ & $90.1(1.9)$ & $91.8(3.5)$ & $93.0(3.5)$ & $91.0 \pm 7.0$ \\
\hline & 200 & $99.3(1.9)$ & $103(0.8)$ & $96.3(1.6)$ & $99.0(0.0)$ & $89.1 \pm 3.1$ \\
\hline \multirow[t]{3}{*}{ 4-CPD } & 2.5 & $99.0(9.2)$ & $92.1(0.9)$ & $96.4(4.8)$ & $95.8(5.8)$ & $92.7 \pm 2.1$ \\
\hline & 25 & $92.6(2.6)$ & $91.8(7.5)$ & $90.1(7.3)$ & $92.0(5.0)$ & $94.4 \pm 6.5$ \\
\hline & 200 & $101(0.5)$ & 97.7 (2.6) & $95.8(1.8)$ & $98.0(0.0)$ & $95.5 \pm 1.8$ \\
\hline \multirow[t]{3}{*}{ MDMA } & 2.5 & $102(5.1)$ & $99.8(2.2)$ & $96.7(3.4)$ & $99.5(3.8)$ & $104.4 \pm 4.9$ \\
\hline & 25 & $95.4(6.9)$ & $92.5(2.4)$ & 94.5 (1.6) & $94.0(3.7)$ & $97.6 \pm 6.6$ \\
\hline & 200 & $100(1.6)$ & $98.7(0.3)$ & $98.0(1.5)$ & $99.0(0.0)$ & $96.9 \pm 4.9$ \\
\hline \multirow[t]{3}{*}{ MDEA } & 2.5 & $96.2(9.0)$ & $97.6(9.7)$ & $97.8(8.3)$ & $97.2(7.0)$ & $104.0 \pm 5.1$ \\
\hline & 25 & $95.8(6.9)$ & $92.0(0.6)$ & $91.4(1.1)$ & $93.0(4.0)$ & $98.4 \pm 6.8$ \\
\hline & 200 & $105(4.3)$ & $101(0.3)$ & $99.9(0.2)$ & $102(0.0)$ & $98.6 \pm 5.1$ \\
\hline \multirow[t]{3}{*}{$\alpha-P V P$} & 2.5 & $102(9.8)$ & $105(10.2)$ & $107(6.1)$ & $105(7.1)$ & $95.4 \pm 3.6$ \\
\hline & 25 & $94.8(8.3)$ & $92.2(4.8)$ & $94.8(5.7)$ & $94.0(5.2)$ & $94.7 \pm 6.9$ \\
\hline & 200 & $101(0.1)$ & $96.3(5.4)$ & $95.2(3.6)$ & $98.0(0.5)$ & $98.8 \pm 3.6$ \\
\hline \multirow[t]{3}{*}{ Methylone } & 2.5 & $102(7.2)$ & $106(2.4)$ & 108 (6.9) & $106(2.7)$ & $96.2 \pm 2.2$ \\
\hline & 25 & $91.1(2.4)$ & $92.6(3.3)$ & $98.1(4.5)$ & 93.9 (3.9) & $94.5 \pm 4.5$ \\
\hline & 200 & $92.6(1.1)$ & $96.7(3.2)$ & $99.4(4.1)$ & $96.2(3.6)$ & $91.1 \pm 3.9$ \\
\hline \multirow[t]{3}{*}{$\alpha-\mathrm{PiHP}$} & 2.5 & $103(9.3)$ & $91.3(4.4)$ & $98.8(2.4)$ & $97.7(7.2)$ & $94.5 \pm 3.0$ \\
\hline & 25 & $93.1(6.2)$ & $95.5(2.0)$ & $95.2(6.8)$ & $95.0(4.4)$ & $96.7 \pm 6.6$ \\
\hline & 200 & $105(2.2)$ & $98.6(6.5)$ & $106(3.2)$ & $103(0.0)$ & $96.9 \pm 0.7$ \\
\hline
\end{tabular}


Table 3 (continued)

\begin{tabular}{|c|c|c|c|c|c|c|}
\hline \multirow[t]{2}{*}{ Analyte } & \multirow[t]{2}{*}{$C$} & \multicolumn{3}{|c|}{ Intraday assay } & \multirow[t]{2}{*}{ Interday assay } & \multirow{2}{*}{$\begin{array}{l}\text { Recovery } \\
(\text { mean } \pm S D)\end{array}$} \\
\hline & & Day 1 & Day 2 & Day 3 & & \\
\hline \multirow[t]{3}{*}{ 4-F-PHP } & 2.5 & $102(10.0)$ & $92.5(3.5)$ & $95.3(5.7)$ & $96.5(7.1)$ & $97.9 \pm 3.4$ \\
\hline & 25 & $89.8(6.3)$ & $92.7(5.5)$ & $93.9(4.2)$ & $92.0(4.7)$ & $94.3 \pm 3.8$ \\
\hline & 200 & $101(0.5)$ & 95.7 (3.9) & $99.6(2.2)$ & $99.0(0.0)$ & $92.7 \pm 4.5$ \\
\hline \multirow[t]{3}{*}{ Butylone } & 2.5 & $94.3(2.6)$ & $94.6(3.3)$ & $91.1(3.1)$ & $93.3(3.0)$ & $89.4 \pm 1.9$ \\
\hline & 25 & $92.3(4.3)$ & $85.8(0.7)$ & $95.2(4.0)$ & $91.0(5.5)$ & $92.6 \pm 3.6$ \\
\hline & 200 & $101(0.1)$ & $98.8(0.4)$ & $96.6(1.5)$ & $99.0(0.0)$ & $88.1 \pm 3.3$ \\
\hline \multirow[t]{3}{*}{$\alpha-\mathrm{PHP}$} & 2.5 & $103(6.3)$ & $112(3.4)$ & $108(6.5)$ & $107(5.7)$ & $91.4 \pm 3.5$ \\
\hline & 25 & $92.2(5.0)$ & $87.4(0.4)$ & $91.2(5.0)$ & $90.0(4.1)$ & $91.5 \pm 8.0$ \\
\hline & 200 & $100(1.4)$ & $106(5.6)$ & $105(3.2)$ & $104(0.0)$ & $96.0 \pm 2.4$ \\
\hline \multirow[t]{3}{*}{ Eutylone } & 2.5 & $92.8(6.5)$ & $91.1(7.7)$ & $96.2(7.6)$ & $93.4(6.2)$ & $92.1 \pm 3.7$ \\
\hline & 25 & $98.8(4.3)$ & $93.8(3.0)$ & $99.3(0.4)$ & $97.0(3.7)$ & $95.1 \pm 5.0$ \\
\hline & 200 & $99.8(0.2)$ & $95.8(3.9)$ & $94.8(3.3)$ & $97.0(0.0)$ & $94.1 \pm 2.3$ \\
\hline \multirow[t]{3}{*}{ Pentylone } & 2.5 & $101(9.5)$ & $94.2(2.4)$ & $95.8(1.1)$ & $96.9(5.5)$ & $97.1 \pm 4.7$ \\
\hline & 25 & $95.5(3.6)$ & $88.4(3.6)$ & $96.6(1.1)$ & $94.0(4.9)$ & $91.2 \pm 3.9$ \\
\hline & 200 & 99.9 (1.6) & $95.1(0.6)$ & $97.6(2.6)$ & $98(0.0)$ & $93.9 \pm 2.7$ \\
\hline \multirow[t]{3}{*}{ 4-Cl- $\alpha-\mathrm{PVP}$} & 2.5 & $99.1(8.5)$ & $95.7(8.5)$ & $102(8.8)$ & $99.0(7.3)$ & $105.8 \pm 4.7$ \\
\hline & 25 & $86.5(0.1)$ & 88.7 (5.9) & $97.4(1.8)$ & $91.0(6.3)$ & $92.2 \pm 10.3$ \\
\hline & 200 & $100(1.3)$ & $100(2.3)$ & $105(4.5)$ & $102(0.0)$ & $96.9 \pm 1.5$ \\
\hline \multirow[t]{3}{*}{ Ephylone } & 2.5 & $99.3(6.1)$ & $92.1(5.0)$ & $93.7(0.1)$ & $95.0(5.0)$ & $100.9 \pm 5.5$ \\
\hline & 25 & $94.1(2.3)$ & $93.1(4.8)$ & $94.9(2.0)$ & $94.0(2.7)$ & $95.4 \pm 1.3$ \\
\hline & 200 & $100(0.8)$ & $94.1(0.2)$ & $98.3(2.2)$ & $98.0(0.0)$ & $96.3 \pm 2.6$ \\
\hline \multirow[t]{3}{*}{ PV4 (MPHP) } & 2.5 & $92.6(9.5)$ & $88.4(8.5)$ & $93.5(9.2)$ & $91.5(7.5)$ & $92.2 \pm 3.1$ \\
\hline & 25 & $94.8(8.5)$ & $88.8(3.5)$ & $95.8(4.7)$ & $93.0(5.9)$ & $93.8 \pm 4.0$ \\
\hline & 200 & $104(2.8)$ & 99.9 (1.8) & $98.6(0.3)$ & $101(0.0)$ & $92.5 \pm 2.3$ \\
\hline \multirow[t]{3}{*}{ PV9 } & 2.5 & $96.9(8.3)$ & $102(7.0)$ & $100(1.1)$ & $99.6(5.3)$ & $89.7 \pm 3.0$ \\
\hline & 25 & $92.2(5.0)$ & $89.3(6.4)$ & $95.8(0.9)$ & $92.0(4.8)$ & $88.2 \pm 3.1$ \\
\hline & 200 & $105(2.7)$ & $109(4.4)$ & $111(1.7)$ & $108(0.0)$ & $94.8 \pm 1.8$ \\
\hline \multirow[t]{3}{*}{ MDPBP } & 5 & $93.0(5.2)$ & $96.5(8.7)$ & $101(0.9)$ & $96.8(5.8)$ & $102.0 \pm 0.1$ \\
\hline & 25 & $93.5(5.1)$ & $90.9(5.1)$ & $92.4(1.3)$ & $92.0(3.5)$ & $92.5 \pm 11.2$ \\
\hline & 200 & $108(2.7)$ & $99.4(3.4)$ & $97.7(1.2)$ & $102(0.0)$ & $96.6 \pm 6.2$ \\
\hline \multirow[t]{3}{*}{ MDPV } & 5 & $108(5.5)$ & $106(1.6)$ & $108(2.8)$ & $107(2.9)$ & $91.9 \pm 1.7$ \\
\hline & 25 & $92.2(4.6)$ & $102(1.8)$ & $102(1.2)$ & $99.0(5.5)$ & $94.2 \pm 6.1$ \\
\hline & 200 & $101(2.5)$ & $101(2.9)$ & $96.3(0.9)$ & $99.0(0.0)$ & $93.6 \pm 2.0$ \\
\hline \multirow[t]{3}{*}{ 3,4-MDPHP } & 2.5 & $96.4(9.0)$ & $113(2.0)$ & $108(0.8)$ & $106(8.1)$ & $102.9 \pm 4.6$ \\
\hline & 25 & $89.3(4.7)$ & $94.4(3.8)$ & $98.2(3.8)$ & $94.0(5.3)$ & $93.8 \pm 4.2$ \\
\hline & 200 & $101(0.8)$ & 98.7 (4.9) & $102(0.7)$ & $101(0.0)$ & $92.3 \pm 2.2$ \\
\hline \multirow[t]{3}{*}{ Naphyrone } & 5 & 105 (4.6) & $95.4(8.0)$ & $101(2.3)$ & $100(5.8)$ & $93.9 \pm 1.7$ \\
\hline & 25 & $89.0(3.5)$ & $99.9(6.3)$ & $95.2(9.2)$ & $95.0(7.4)$ & $88.9 \pm 0.6$ \\
\hline & 200 & $105(1.8)$ & $104(4.6)$ & $105(1.0)$ & $105(0.0)$ & $91.2 \pm 3.4$ \\
\hline
\end{tabular}

Each value was obtained from six replicate experiments. The precision data are given in parenthesis as $\%$ coefficient of variation

$C$ nominal concentration in $\mathrm{ng} / \mathrm{mL}, S D$ standard deviation

To the best of our knowledge, the present work is the first attempt at applying GC-MS/MS for the analysis of NPS in blood samples. Most importantly, the proposed procedure offers many advantages, including enhanced sensitivity and selectivity (compared to other GC-based methods). In toxicological analyses, the small volume of available sample, which in some cases is delivered to the laboratory, may mean that only a few tests can be conducted. Under the developed procedure, a small volume of sample $(0.2 \mathrm{~mL})$ provided the required sensitivity (low LODs and LOQs were achieved). Compared to the literature data, similar sample volumes have been used $(0.1-0.2 \mathrm{~mL})$, but those methods require a 
more expensive and complicated LC-MS/MS-based analysis $[8,32]$ or sophisticated sample preparation methods (e.g., SPME; required sample volume of $0.05 \mathrm{~mL}$ ) [33]. In other GC-based methods with LLE or solid-phase extraction (SPE) as the sample preparation method, the sample volume is typically between $1-2 \mathrm{~mL}$, because of the use of single-stage quadrupole detection instead of MS/MS [3, 34]. In such methods, the LODs and LOQs are not as low as in our procedure, which makes these methods not sufficiently sensitive for NPS analysis. Additionally, in LLE- and SPE-based procedures followed by GC analysis, a relatively large volume of organic solvent is used for extraction and conditioning/elution of the SPE cartridges. In our developed method, the volume of solvent used $(1 \mathrm{~mL})$ was similar to that required for LC-MS/MS-based methods.

There are limited data available concerning multi-component methods for the analysis of cathinone derivatives using GC-MS, and most of the available literature is limited to case reports of intoxications [34] or the optimization of derivatization processes [25]. To the best of our knowledge, based on previous reports, the maximum number of ATSs and NPS that can be quantified by GC-MS in a single analytical run was 26 [3]. In multi-component methods for NPS analysis, LC-MC/MS is typically used [10, 32]. In such methods, the LODs and LOQs range from below $0.1 \mathrm{ng} /$ $\mathrm{mL}$ up to a few $\mathrm{ng} / \mathrm{mL}$. These values are comparable with those obtained in our study. However, GC-MS/MS is clearly a more environmentally friendly technique. Thus, the proposed method can be used as an alternative to LC-MS/MS method, offering similar sensitivity and selectivity.

\section{Analysis of real samples}

After validation, to demonstrate the utility of the developed procedure for the quantification of a wide variety of psychoactive substances in routine toxicological analyses, authentic blood samples that had previously tested positive for the substances included in this study were analysed. A summary of the quantitative results for the forensic case samples is presented in Table 4.

Under the developed procedure, one nonfatal [case 1, driving under the influence (DUI) of drugs] and seven fatal (cases 2-8) forensic cases were analyzed. In our study, four drugs related to ATSs, namely, amphetamine, ephedrine, pseudoephedrine, and MDMA, and nine drugs related to NPS, namely, 4-CMC, 4-MEC, hex-en, $\alpha$-PiHP, 4-F-PHP, 4-Cl- $\alpha$-PVP, ephylone, PV4, and 3,4-MDPHP, were quantified. Two compounds (pentedrone and pentylone) were detected below the LOQ. The most common drugs present were AM ( 4 cases) and hex-en ( 4 cases).

Only in one case (no. 7) was a single drug quantified in the investigated blood samples. The case was related to the death of a young man during police intervention. Based on an analysis of the documents accompanying the samples, the man was aggressive, highly stimulated, had hallucinations, and died suddenly (autopsy revealed that the immediate cause of death was acute cardiac failure). The determined concentration of the NPS (PV4), considering the man's behaviour described above and the resulting death, was considered high and fatal. In the other seven forensic cases investigated, at least two psychoactive substances related to ATSs and/or NPS were quantified. In addition, in these cases, other substances, such as alcohol or pharmaceuticals, were also found (data shown in Table 4). Importantly, interpreting the results of the ATS determinations is not complicated because there are many data describing nontoxic, toxic, or fatal concentrations of such drugs typically determined in blood samples. For example, the concentrations of AM in cases no. 4 and no. 5 were determined to be in the toxic range, especially for nonaddictive individuals [35]. Estimating the concentrations of NPS in various types of forensic cases (nonfatal, toxic, or fatal) can be challenging. It is very difficult to estimate cutoff toxic values for NPS due to the low number of data available in the scientific literature on this topic. Therefore, the majority of the postmortem cases analyzed in our study can be considered intoxication by a mixture of NPS and/or ATSs.

The obtained results showed that drug users typically take more than one drug at the same or similar time. It is also possible to unconsciously ingest multiple psychoactive substances because the drugs sold on the black market are typically mixtures of compounds with unknown compositions. Ingesting multiple drugs with similar physicochemical properties (such as ATSs and cathinones) may lead to drugdrug interactions, such as additive or synergism effect, and there is the potential for dangerous effects that can not be foreseen by the user.

In conclusion, the concentrations of the compounds of interest determined in the investigated blood samples were in a range of below the LOQ to $611 \mathrm{ng} / \mathrm{mL}$. This means that each newly developed method for drug determination should be sufficiently sensitive and be able to quantify analytes over a wide concentration range.

\section{Conclusions}

A simple and rapid LLE procedure with GC-MS/MS analysis was developed for the quantification of 45 of the most commonly reported drugs of abuse related to ATSs and synthetic cathinones in whole blood samples using $200 \mu \mathrm{L}$ of sample and a total of $1 \mathrm{~mL}$ of extraction solvent. The presented method was successfully validated according to international guidelines in the field of our study. The procedure met the established validation parameters, meaning that it is suitable for the quantification of even trace 
Table 4 Summary of quantitative results for authentic case samples (mean $\pm \mathrm{SD} \mathrm{ng} / \mathrm{mL}$ )

\begin{tabular}{|c|c|c|c|c|c|c|c|c|}
\hline & Case 1 & Case 2 & Case 3 & Case 4 & Case 5 & Case 6 & Case 7 & Case 8 \\
\hline Sampling date & 11 Aug. 2017 & 26 Sep. 2017 & 06 Sep. 2017 & 13 Nov. 2017 & 03 Jan. 2018 & 12 Jun. 2017 & 11 Aug. 2017 & 18 Oct. 2017 \\
\hline Gender & Male & Male & Male & Female & Male & Female & Male & Female \\
\hline Age (years) & 22 & No Data & 40 & 23 & 31 & 19 & 29 & 21 \\
\hline Case type & Nonfatal & Fatal & Fatal & Fatal & Fatal & Fatal & Fatal & Fatal \\
\hline \multicolumn{9}{|c|}{ Quantified compounds } \\
\hline $\begin{array}{l}\text { Ampheta- } \\
\text { mine }\end{array}$ & $89.5 \pm 3.2$ & $17.87 \pm 0.82$ & & $450 \pm 18$ & $238.2 \pm 2.4$ & & & \\
\hline Ephedrine & & & $2.29 \pm 0.11$ & & & & & \\
\hline $\begin{array}{l}\text { Pseu- } \\
\text { doephed- } \\
\text { rine }\end{array}$ & & & $3.86 \pm 0.39$ & & & & & \\
\hline Pentedrone & & & & $<\mathrm{LOQ}$ & & & & \\
\hline 4-CMC & & & & $2.51 \pm 0.19$ & & $45.0 \pm 1.3$ & & \\
\hline 4-MEC & & & & $6.43 \pm 0.45$ & & & & \\
\hline Hex-en & & $8.79 \pm 0.64$ & & $7.25 \pm 0.42$ & $34.4 \pm 1.1$ & & & $3.79 \pm 0.11$ \\
\hline MDMA & & & & & $18.04 \pm 0.63$ & & & \\
\hline$\alpha-\mathrm{PiHP}$ & & & & & & & & $611 \pm 17$ \\
\hline 4-F-PHP & & & & & $12.62 \pm 0.19$ & & & \\
\hline Pentylone & & & & & & $<\mathrm{LOQ}$ & & \\
\hline 4-Cl- $\alpha-\mathrm{PVP}$ & $2.41 \pm 0.47$ & & & & $9.01 \pm 0.32$ & & & $10.53 \pm 0.34$ \\
\hline Ephylone & & & & & & $1.32 \pm 0.11$ & & \\
\hline PV4 & & & & & & & $291.3 \pm 6.1$ & $6.11 \pm 0.18$ \\
\hline 3,4-MDPHP & & & & & $65.1 \pm 1.3$ & & & $7.11 \pm 0.33$ \\
\hline $\begin{array}{l}\text { Other identi- } \\
\text { fied drugs }\end{array}$ & $\begin{array}{l}\text { THC, THC- } \\
\text { COOH }\end{array}$ & $\begin{array}{l}\text { Diazepam; } \\
\text { nordazepam; } \\
\text { temazepam }\end{array}$ & $\begin{array}{l}\text { 6-AM, } \\
\text { morphine, } \\
\text { codeine, } \\
\text { methadone, } \\
\text { ethanol }\end{array}$ & $\begin{array}{l}\text { Morphine, } \\
\text { codeine, } \\
\text { dextrometor- } \\
\text { phan, trama- } \\
\text { dol, cocaine, } \\
\text { EME, BE, } \\
\text { alprazolam, } \\
\text { diazepam, } \\
\text { nordazepam, } \\
\text { oxazepam, } \\
\text { temazepam, } \\
\text { THC, THC- } \\
\text { COOH }\end{array}$ & $\begin{array}{l}\text { Isopropyl- } \\
\text { phenidate, } \\
\text { THC, THC- } \\
\mathrm{COOH}\end{array}$ & $\begin{array}{l}\text { Etizolam, } \\
\text { U-47700, } \\
\text { dex- } \\
\text { tromethor- } \\
\text { phan }\end{array}$ & - & $\begin{array}{l}\text { U-47700, } \\
\text { etizolam }\end{array}$ \\
\hline
\end{tabular}

THC $\Delta^{9}$-tetrahydrocannabinol, THCCOOH 11-nor-9-carboxy- $\Delta^{9}$-tetrahydrocannabinol, 6-AM 6-acetylmorphine, EME ecgonine methyl ester, $B E$ benzoylecgonine

amounts of NPS and related drugs in the most commonly used whole blood in forensic toxicology. The proposed protocol had acceptable ranges of accuracy and repeatability, and the low LODs and LOQs proved high sensitivity of the method. The developed method can be a less expensive and more ecologically friendly alternative to LC-MS/MS-based methods. Our proposed method can also be easily modified for the analysis of additional compounds with similar physicochemical properties (since the analytes are extracted from an alkaline environment). Moreover, GC-MS/MS techniques are becoming increasingly popular for toxicology analysis of biological samples, which makes the method readily applicable in a number of laboratories. The presented procedure was successfully applied for the analysis of whole blood samples in several toxicological cases (both fatal and nonfatal), which proved the utility of the method.

Acknowledgement This work was supported in part by the program "Opus 10" awarded for the years $2016-2019$ by the National Science Centre, Poland (project no: 2015/19/B/ST4/02725).

\section{Compliance with ethical standards}

Conflict of interest The authors declare that they have no conflict of interest. 
Ethical approval All blood collections from living suspects and deceased were made by judicial authorities, and the samples were sent to our forensic science department for routine toxicology analysis. All analyses were made according to the request of judicial authorities.

Open Access This article is distributed under the terms of the Creative Commons Attribution 4.0 International License (http://creativeco mmons.org/licenses/by/4.0/), which permits unrestricted use, distribution, and reproduction in any medium, provided you give appropriate credit to the original author(s) and the source, provide a link to the Creative Commons license, and indicate if changes were made.

\section{References}

1. Woźniak MK, Wiergowski M, Aszyk J, Kubica P, Namieśnik J, Biziuk M (2018) Application of gas chromatography-tandem mass spectrometry for the determination of amphetamine-type stimulants in blood and urine. J Pharm Biomed Anal 148:58-64. https://doi.org/10.1016/j.jpba.2017.09.020

2. European Monitoring Centre for Drugs and Drug Addiction (EMCDDA) (2018) European drug report 2018: trends and developments. Publications Office of the European Union, Louxembourg. http://www.emcdda.europa.eu/system/files/publi cations/8585/20181816_TDAT18001ENN_PDF.pdf. Accessed 1 Mar 2019

3. Mercieca G, Odoardi S, Cassar M, Rossi SS (2018) Rapid and simple procedure for the determination of cathinones, amphetamine-like stimulants and other new psychoactive substances in blood and urine by GC-MS. J Pharm Biomed Anal 149:494501. https://doi.org/10.1016/j.jpba.2017.11.024

4. Concheiro M, Castaneto M, Kronstrand R, Huestis MA (2015) Simultaneous determination of 40 novel psychoactive stimulants in urine by liquid chromatography-high resolution mass spectrometry and library matching. J Chromatogr A 1397:3242. https://doi.org/10.1016/j.chroma.2015.04.002

5. Tomczak E, Woźniak MK, Kata M, Wiergowski M, Szpiech B, Biziuk M (2018) Blood concentrations of a new psychoactive substance 4-chloromethcathinone (4-CMC) determined in 15 forensic cases. Forensic Toxicol 36:476-485. https://doi. org/10.1007/s11419-018-0427-8

6. Swortwood MJ, Boland DM, DeCaprio AP (2013) Determination of 32 cathinone derivatives and other designer drugs in serum by comprehensive LC-QQQ-MS/MS analysis. Anal Bioanal Chem 405:1383-1397. https://doi.org/10.1007/s0021 6-012-6548-8

7. Alsenedi KA, Morrison C (2018) Determination of amphetamine-type stimulants (ATSs) and synthetic cathinones in urine using solid phase micro-extraction fibre tips and gas chromatography-mass spectrometry. Anal Methods 10:1431-1440. https:// doi.org/10.1039/c8ay00041g

8. Adamowicz P, Tokarczyk B (2016) Simple and rapid screening procedure for 143 new psychoactive substances by liquid chromatography-tandem mass spectrometry. Drug Test Anal 8:652-667. https://doi.org/10.1002/dta.1815

9. Mogollón NGS, Quiroz-Moreno CD, Prata PS, de Almeida JR, Cevallos AS, Torres-Guiérrez R, Augusto F (2018) New advances in toxicological forensic analysis using mass spectrometry techniques. J Anal Methods Chem 2018:4142527. https://doi.org/10.1155/2018/4142527

10. Vaiano F, Busardò FP, Palumbo D, Kyriakou C, Fioravanti A, Catalani V, Mari F, Bertol E (2016) A novel screening method for 64 new psychoactive substances and 5 amphetamines in blood by LC-MS/MS and application to real cases.
J Pharm Biomed Anal 129:441-449. https://doi.org/10.1016/j. jpba.2016.07.009

11. Tobiszewski M, Mechlińska A, Zygmunt B, Namieśnik J (2009) Green analytical chemistry in sample preparation for determination of trace organic pollutants. Trends Analyt Chem 28:943951. https://doi.org/10.1016/j.trac.2009.06.001

12. Moreno I, Barroso M, Martinho A, Cruz A, Gallardo E (2015) Determination of ketamine and its major metabolite, norketamine, in urine and plasma samples using microextraction by packed sorbent and gas chromatography-tandem mass spectrometry. J Chromatogr B 1004:67-78. https://doi.org/10.1016/j. jchromb.2015.09.032

13. Dybowski MP, Dawidowicz AL (2018) Application of the QuEChERS procedure for analysis of $\Delta^{9}$-tetrahydrocannabinol and its metabolites in authentic whole blood samples by GCMS/MS. Forensic Toxicol 36:415-423. https://doi.org/10.1007/ s11419-018-0419-8

14. Rosado T, Fernandes L, Barroso M, Gallardo E (2017) Sensitive determination of THC and main metabolites in human plasma by means of microextraction in packed sorbent and gas chromatography-tandem mass spectrometry. J Chromatogr B 1043:63-73. https://doi.org/10.1016/j.jchromb.2016.09.007

15. Kinani S, Bouchonnet S, Milan N, Ricordel I (2007) A sensitive and selective method for the detection of diazepam and its main metabolites in urine by gas chromatography-tandem mass spectrometry. J Chromatogr A 1141:131-137. https://doi. org/10.1016/j.chroma.2006.12.008

16. Cartiser N, Bévalot F, Le Meur C, Gaillard Y, Malicier D, Hubert N, Guitton J (2011) Gas chromatography-tandem mass spectrometry assay for the quantification of four benzodiazepines and citalopram in eleven postmortem rabbit fluids and tissues, with application to animal and human samples. J Chromatogr B 879:2909-2918. https://doi.org/10.1016/j.jchromb.2011.08.023

17. Levitas MP, Andrews E, Lurie I, Marginean I (2018) Discrimination of synthetic cathinones by GC-MS and GC-MS/MS using cold electron ionization. Forensic Sci Int 288:107-114. https:// doi.org/10.1016/j.forsciint.2018.04.026

18. Busardò FP, Kyriakou C, Tittarelli R, Mannocchi G, Pantano F, Santurro A, Zaami S, Baglìo G (2015) Assessment of the stability of mephedrone in ante-mortem and post-mortem blood specimens. Forensic Sci Int 256:28-37. https://doi.org/10.1016/j.forsc iint.2015.07.021

19. Nowak K, Szpot P, Zawadzki M (2019) Unstability of 4-CMC in human serum specimen. Forensic Toxicol 37:261-264. https://doi. org/10.1007/s11419-018-0455-4

20. Johnson RD, Botch-Jones SR (2013) The stability of four designer drugs: MDPV, mephedrone, BZP and TFMPP in three biological matrices under various storage conditions. J Anal Toxicol 37:51-55. https://doi.org/10.1093/jat/bks138

21. Rivier L (2003) Criteria for the identification of compounds by liquid chromatography-mass spectrometry and liquid chromatography-multiple mass spectrometry in forensic toxicology and doping analysis. Anal Chim Acta 492:69-82. https://doi.org/10.1016/ S0003-2670(03)00889-4

22. Scientific Working Group for Forensic Toxicology (2013) Scientific working group for forensic toxicology (SWGTOX) standard practices for method validation in forensic toxicology. J Anal Toxicol 37:452-474. https://doi.org/10.1093/jat/bkt054

23. US Food and Drug Administration (1996) Guidance for industry. Q2B validation of analytical procedures: methodology. https ://www.fda.gov/downloads/drugs/guidances/ucm073384.pdf. Accessed 1 Mar 2019

24. Adamowicz P, Malczyk A (2019) Stability of synthetic cathinones in blood and urine. Forensic Sci Int 295:36-45. https://doi. org/10.1016/j.forsciint.2018.12.001 
25. Alsenedi KA, Morrison C (2017) Comparison of six derivatizing agents for the determination of nine synthetic cathinones using gas chromatography-mass spectrometry. Anal Methods 9:2732-2743. https://doi.org/10.1039/c7ay00597k

26. Adamowicz P, Gieroń J, Gil D, Lechowicz W, Skulska A, Tokarczyk B (2016) 3-Methylmethcathinone-interpretation of blood concentrations based on analysis of 95 cases. J Anal Toxicol 40:272-276. https://doi.org/10.1093/jat/bkw018

27. Kim SY, Kim JY, Kwon W, In MK, Kim YE, Paeng K-J (2013) Method development for simultaneous determination of amphetamine type stimulants and cannabinoids in urine using GC-MS. Microchem J 110:326-333. https://doi.org/10.1016/j.micro c. 2013.04 .004

28. Kerrigan S, Savage M, Cavazos C, Bella P (2016) Thermal degradation of synthetic cathinones: implications for forensic toxicology. J Anal Toxicol 40:1-11. https://doi.org/10.1093/jat/bkv099

29. Aszyk J, Kot J, Tkachenko Y, Woźniak M, Bogucka-Kocka A, Kot-Wasik A (2017) Novel liquid chromatography method based on linear weighted regression for the fast determination of isoprostane isomers in plasma samples using sensitive tandem mass spectrometry detection. J Chromatogr B 1051:17-23. https://doi. org/10.1016/j.jchromb.2017.02.021

30. Rajski Ł, Lozano A, Uclés A, Ferrer C, Fernández-Alba AR (2013) Determination of pesticide residues in high oil vegetal commodities by using various multi-residue methods and clean-ups followed by liquid chromatography tandem mass spectrometry. J Chromatogr A 1304:109-120. https://doi. org/10.1016/j.chroma.2013.06.070

31. Zawilska JB, Wojcieszak J (2017) $\alpha$-Pyrrolidinophenones: a new wave of designer cathinones. Forensic Toxicol 35:201-216. https ://doi.org/10.1007/s11419-016-0353-6

32. Ammann D, McLaren JM, Gerostamoulos D, Beyer J (2012) Detection and quantification of new designer drugs in human blood: part 2-designer cathinones. J Anal Toxicol 36:381-389. https://doi.org/10.1093/jat/bks049

33. Saito T, Namera A, Osawa M, Aoki H, Inokuchi S (2013) SPMEGC-MS analysis of $\alpha$-pyrrolidinovaleorophenone in blood in a fatal poisoning case. Forensic Toxicol 31:328-332. https://doi. org/10.1007/s11419-013-0183-8

34. Olesti E, Pujadas M, Papaseit E, Pérez-Mañá C, Pozo ÓJ, Farré M, de la Torre R (2017) GC-MS quantification method for mephedrone in plasma and urine: application to human pharmacokinetics. J Anal Toxicol 41:100-106. https://doi.org/10.1093/jat/bkw120

35. Molina DK (2009) Handbook of forensic toxicology for medical examiners: practical aspects of criminal and forensic investigations, 1st edn. CRC Press, Boca Raton

Publisher's Note Springer Nature remains neutral with regard to jurisdictional claims in published maps and institutional affiliations. 